\title{
Research of near-wall thermodynamic state for indoor airflow over the vertical heating unit using TIV/PIV/RTD
}

Article

Accepted Version

Creative Commons: Attribution-Noncommercial-No Derivative Works 4.0

Wu, Q., Luo, Z. and Liu, J. (2019) Research of near-wall thermodynamic state for indoor airflow over the vertical heating unit using TIV/PIV/RTD. Building and Environment, 165. 106406. ISSN 0360-1323 doi:

https://doi.org/10.1016/j.buildenv.2019.106406 Available at https://centaur.reading.ac.uk/86134/

It is advisable to refer to the publisher's version if you intend to cite from the work. See Guidance on citing.

To link to this article DOI: http://dx.doi.org/10.1016/j.buildenv.2019.106406

Publisher: Elsevier

All outputs in CentAUR are protected by Intellectual Property Rights law, including copyright law. Copyright and IPR is retained by the creators or other copyright holders. Terms and conditions for use of this material are defined in the End User Agreement.

www.reading.ac.uk/centaur 
Central Archive at the University of Reading

Reading's research outputs online 


\title{
Research of near-wall thermodynamic state for indoor airflow over the vertical heating unit using TIV/PIV/RTD
}

\author{
Qing $\mathrm{Wu}^{\mathrm{a}}{ }^{\mathrm{b}}$, Zhiwen Luo ${ }^{\mathrm{c}, *}$, Jing Liu ${ }^{\mathrm{a}, \mathrm{b}, *}$ \\ ${ }^{a}$ School of Architecture, Harbin Institute of Technology, Harbin 150000, China. \\ ${ }^{b}$ Key Laboratory of Cold Region Urban and Rural Human Settlement Environment Science and \\ Technology, Ministry of Industry and Information Technology, Harbin 150000, China. \\ ${ }^{c}$ School of the Built Environment, University of Reading, UK
}

Abstract: Up to now, few studies focus on thermodynamic state including the velocity and temperature of the air near heating unit. The thermodynamic state of the airflow over an indoor heating unit has a significant influence on indoor thermal comfort and energy consumption. This study analyzed the thermal and dynamic state of the near-wall airflow over the heating unit. The thermal state was measured using resistance thermal detectors (RTDs). The near-wall airflow field were measured by particle image velocimetry (PIV) and TIV. The performance of TIV in natural and mixed convection were evaluated by comparing the TIV and PIV measurement results. Under natural convection, the velocity shows vertical variation and the spatial difference changes more pronounced with the increase of heating temperature. Under mixed convection, the near-wall temperature changes uniform and the velocity exhibits a decreasing trend with the increase of height. Through the spectrum analysis of the temperature, it is found that the velocity measured by TIV is close to the velocity near the boundary layer to some content. The positions of the near-surface velocity measured by TIV are not fixed in all cases and change with the change of the boundary layer. The findings in this study can provide a convenient and feasible flow field measurement method suitable for actual space scale. This method can predict the effect of heating terminal units on indoor airflow and thermal environment, so as to optimize the form and arrangement of the heating terminal units, and improve heating efficiency and occupants' thermal comfort.

Keywords: Indoor velocity measurement; Near-wall airflow; Temperature distribution; Heating unit; Thermal image velocimetry

*Corresponding author: Jing Liu, Zhiwen Luo

Address: School of Architecture, Harbin Institute of Technology, No.66, Xidazhi Street, Nangang District, Harbin 150000, China (J. Liu).

Tel./fax: +86 045186282123 .

E-mail: liujinghit0@163.com (J. Liu), z.luo@ reading.ac.uk (Z. Luo). 
Indoors, due to natural convection, thermal plumes are formed in the vicinity of conventional vertical heating units such as panel or column radiators. In recent years, to improve the thermal efficiency of a typical vertical heating unit, some researchers imposed ventilation to heating units and analyzed the performance of the ventilation heating unit [1][2]. Under this circumstance, the flow process of the airflow over the vertical heating unit can be described as natural or mixed convection. Although the effect of influencing factors such as the surface temperature [3], the location of heating unit [4], the shape of heating unit [5], and the ventilation condition [1][2] on the distribution of indoor environmental parameters such as air temperature and air velocity in the room, have been systematically analyzed. Most of the previous studies have focused on the distributions of indoor air velocity and air temperature, and few studies have focused on the thermodynamic state near the heating unit yet. The flow and the corresponding heat transfer around the surface of heating unit are important factors that determine the distributions of indoor air velocity and air temperature. Generally, radiators are arranged against the wall under the external window. The thermal insulation of windows is insufficient compared to other envelopes, and more heat is lost through the window [6]. In addition, cold radiation caused by the window heat is then lost from the exterior wall. A part of the heated air flow to the inner of the room due to the insufficient thermal buoyancy and exchange heat with the other air and surfaces of the room. Therefore, the thermodynamic state of the air near the radiator directly affects the heat transfer process among the air and surfaces in the room and the discomfort brought by the cold window 
radiation. Precise estimation of the thermodynamic state of the airflow over the heating unit in a room is of great significance for better understanding the thermal characteristics of an indoor heating system [7][8][9].

To evaluate the thermodynamic state of the airflow over a heating unit, accurate measurement is necessary. The current air temperature measurements are mainly conducted using the resistance of thermal detectors (RTDs) or thermocouples. The air temperature measurement can be easily performed owing to the high frequency, short response time and the ability to store large amount of data of the temperature sampling instruments. On the other side, the velocity measurement methods are mainly divided into two kinds: the point-wise and the globe-wise measurement methods [10]. The point-wise measurement method can only reflect the velocity of the representable points instead of the spatial distribution, and the measured data of measurement points is mostly used as validation or boundary condition of numerical simulation. The globe-wise measurement method can visualize the flow field [11]. Particle image velocimetry (PIV) is a typical and the most widely used flow visualization method. The adjustment of laser and, camera, tracer particle concentration, and image processing all require certain expert knowledge [12]. Moreover, PIV measurement system components are complex and fragile, and thus not suitable for movement; therefore, this method is mostly used in laboratory research. Except some special cases [13][14], traditional velocity measurement methods are rarely applied successfully in the flow field measurement near the indoor heated surface. Besides the complexity of the indoor environment, one of the main reasons for this is the limitation of various velocity measurement technologies, which are explained in detail in [15].

The contradiction between the limitations of existing point-wise or globe-wise measurement 
methods and the need to measure specific surface velocity has been increasing, and researchers are now seeking other velocity measurement methods. The interaction of surface turbulent structures with surface temperature fluctuations has been draw attention gradually. The turbulent structures sweep the interface and give rise to surface temperature fluctuations [16][17]. Recent studies have revealed that the characteristic of the near-surface airflow can be indirectly deduced based on surface high frequency temperature fluctuations. In terms of the acquisition of high frequency temperature fluctuations, thermal infrared camera is more advantageous owing to its high sensitivity, short response time, and spatial resolved capability, in comparison with thermocouple or resistance temperature detectors [18]. As a result, infrared thermography is gradually used as an alternative tool for evaluating near-surface flow distributions. In the current study, the use of infrared thermography in obtaining the characteristic of the near-surface airflow is mainly based on three methods. a) Theoretically establishing the correlation between near-surface velocity and temperature fluctuations based on the surface renewal (SR) theory [16]. The near-surface flow structures are composed of eddies with various sizes that fluctuate with various frequencies and continuously eject and sweep back to the surface. As continuously interacting with the interface, the near-wall flow structures leave traces in the form of surface temperature fluctuations. In addition, the near-surface eddies are distributed according to specific distribution laws [19]. By exacting the eddy distribution parameters from the high frequency surface temperature fluctuations, in combination with the relation between the surface velocity and near-wall heat transfer, the near surface velocity can be deduced [19]. b) The other one is noted as TIV (thermal image velocimetry). This method is similar to the PIV method, which estimates the near-surface velocity by analyzing the displacements of the surface thermal spots within consecutive frames 
captured by the infrared thermal camera. The basic principal and preliminary application of this method can be referred in [15]. c) The last method is also based on the surface renewal theory. Unlike the first method, the near-surface turbulent state is deduced according to the correlation between the surface temperature fluctuations and the intermittent near-surface eddies and no quantitative velocity is acquired.

Table. 1. Application of infrared thermography in near-surface velocity measurement

\begin{tabular}{cccccc}
\hline Object & Indoor/Outdoor & Scale model/ Field & Methods & Velocity Range & Reference \\
\hline Horizontal plate & Indoor & Scale model & (a) & $0.6-4 \mathrm{~m} / \mathrm{s}$ & {$[19]$} \\
Evaporation plate & Indoor & Scale model & (a) & $0-0.5 \mathrm{~m} / \mathrm{s}$ & {$[20]$} \\
Vertical plate & Indoor & Scale model & (b) & $0-0.3 \mathrm{~m} / \mathrm{s}$ & {$[15]$} \\
River & Outdoor & Field & (b) & $0.9-1.1 \mathrm{~m} / \mathrm{s}$ & {$[21]$} \\
Volcano & Outdoor & Field & (b) & - & {$[22]$} \\
Solar tower & Outdoor & Field & (b) & - & {$[23]$} \\
River & Outdoor & Field & (b) & $0-4 \mathrm{~m} / \mathrm{s}$ & {$[24]$} \\
Wall & Outdoor & Field & (b) & $0-2 \mathrm{~m} / \mathrm{s}$ & {$[25]$} \\
Horizontal plate & Outdoor & Scale model & (b) & $0-0.005 \mathrm{~m} / \mathrm{s}$ & {$[26]$} \\
Lava & Outdoor & Field & (b) & $0-0.006 \mathrm{~m} / \mathrm{s}$ & {$[27]$} \\
Artificial turf ground & Outdoor & Field & (c) & - & {$[28]$} \\
Vineyard & Outdoor & Field & (c) & - & {$[29]$} \\
Ground & Outdoor & Field & (c) & - & {$[30]$} \\
\hline
\end{tabular}

101 1. (a), (b) and (c) denote the three methods descripted above.

102 2. Scale model and field denote the scale model experiment and the field measurement

Table. 1 summarizes the current main applications of infrared thermography in near-surface

104 velocity measurement. The first method obtains the near-surface spatial-averaged velocity. For

105 some specific situations, especially the flow field above the heat source, the spatial-averaged flow

106 velocity cannot reflect the spatial distribution characteristics of velocity, and thus the application

107 of this method is limited. The third method can only provide the qualitative velocity and is not

108 suitable for the evaluation of velocity distribution. Compared with the other two methods, the

109 second method can acquire the near-wall two-dimensional velocity distribution and is the most

110 widely used. As shown in Table. 1, TIV is mostly used in outdoor research at present. For both the 
111 indoor and outdoor environment, the primary condition for applying TIV is that the target surface

112 should guarantee certain temperature fluctuations. In outdoor studies, especially for targets such as

113 lava or solar tower, the temperature fluctuation is intense, which is conducive to the application of

114 TIV. Nevertheless, there are still some conditions that cannot meet the temperature fluctuation

115 requirement. In some outdoor studies [25], a blackened polystyrene board was pasted on the

116 observed surface when the target surface temperature fluctuation was small. The heat capacity of

117 the polystyrene board is small and the blackened surface absorbs more solar energy. Through

118 using this method, the surface temperature fluctuations increase greatly. Compared with the

119 outdoor applications, the utilization of TIV in indoor research is more difficult because of the

120 small temperature fluctuations that occur in indoor environments. In the micro-environment over

121 the heating unit, the air near the heating unit is heated and rises vertically under the buoyancy

122 force. In addition, the vertical wall near the heating unit is generally colder than the heated air, and

123 heat is transferred from air to the wall [3]. Owing to the combined effect of the vertical cold wall

124 and the heating unit, the unique thermodynamic state of the airflow is formed. If the black-painted

125 benzene board is placed on the cold wall, it will inevitably affect the original heat transfer process,

126 and make the result deviate from the actual flow to some extent. In addition, most velocity

127 information obtained in the references summarized in Table. 1 is not validated by the other kinds

128 of mature measurement methods, and the precision of the results measured by TIV cannot be

129 guaranteed. Therefore, TIV is in its early stages of development, and its considerable potential is

130 unexplored.

131 In our earlier work, we proposed a TIV-based method for indoor environments and verified

132 the feasibility of the method for velocity measurement under natural convection [15]. However, 
the thermodynamic state of the airflow over the heating unit and the relationship between the thermodynamic state of the airflow and heating temperature and ventilation condition has not been extensively explored yet. This is a subsequent study of [15] and the following questions are explored:

1. The performance of TIV under natural convection and mixed convection.

2. The characteristic of the thermodynamic state of the airflow near the heating unit when the heating temperature changes or mechanical ventilation is imposed.

\section{Methodology}

\subsection{Experimental setup and procedure}

Experiments were performed in a closed rectangular cavity shown in Fig. 1. The coordinate axes are shown in Fig. 1. The cavity was placed in an air-conditioned room whose temperature was maintained at $20-21^{\circ} \mathrm{C}$. The cavity had an internal dimension of $1200(\mathrm{~L}) \times 500(\mathrm{~W}) \times 1400$ (H) $\mathrm{mm}$. The walls were made of transparent Plexiglas. The emissivity of the cavity surfaces was estimated using the infrared thermal camera and a calibrated thermocouple, and was equal to 0.90 . An electric heating unit of which the dimension was $500(\mathrm{~W}) \times 400(\mathrm{H}) \mathrm{mm}$, was attached to the lower part of the vertical wall as a vertical heating element. A 5 - mm - thick polyvinyl chloride with a thermal conductivity of $0.2 \mathrm{~W} /(\mathrm{m} \cdot \mathrm{K})$, was stuck between the heating unit and the vertical wall to decrease heat conduction from the heating unit to the back of the vertical wall. The cavity was connected to the air duct, and a fan provided mechanical ventilation from the ventilation inlet positioned at the bottom of the cavity. The size of the ventilation inlet and outlet was $500(\mathrm{~W}) \times 20$ (H) $\mathrm{mm}$. The heating unit was under the control of an electronic thermostat. The experimental 


\begin{tabular}{lccc}
\hline & $\begin{array}{c}\text { Surface temperature of heating unit } \\
\left({ }^{\circ} \mathrm{C}\right)\end{array}$ & $\begin{array}{c}\text { Ventilation velocity } \\
(\mathrm{m} / \mathrm{s})\end{array}$ & Heat transfer form \\
\hline Case 1 & 45 & 0 & Natural convection \\
Case 2 & 65 & 0 & Natural convection \\
Case 3 & 65 & 1.75 & Mixed convection \\
\hline
\end{tabular}

cases, shown in Table. 2, were set by adjusting the heating temperature of the heating unit and the ventilation velocity.

Before the temperature and velocity measurements can be taken, it takes six hours in advance to reach a steady state for temperature and flow fields. As shown in Fig. 1, one RTD mounted at the ventilation outlet was used to measure the air temperature continuously. Once the sampled temperature stabilized and the temperature fluctuation was less than $0.1{ }^{\circ} \mathrm{C} / \mathrm{min}$ [31], it was assumed that a stable thermodynamic state within the cavity has been reached, and the measurements were taken.

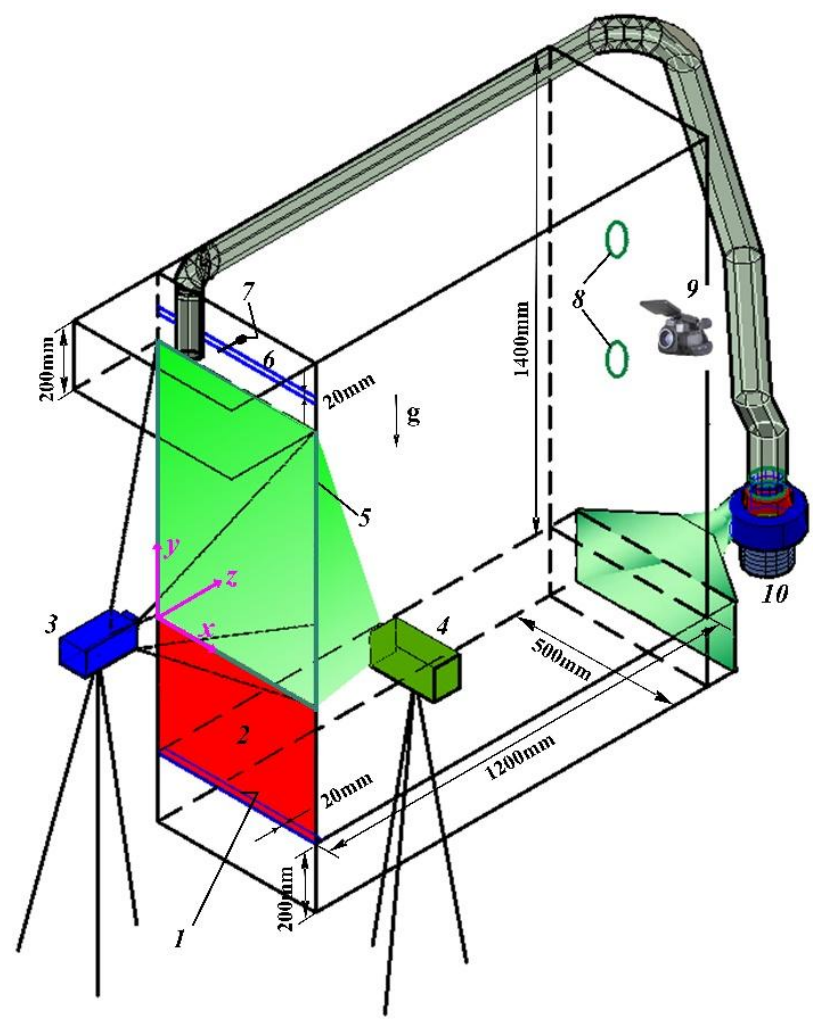




\subsection{Measurements and data processing}

\subsubsection{PIV measurement}

$8 \mathrm{~mm}$ and $15 \mathrm{~mm}$ away from the vertical surface behind the heating unit. The entire visualized area,

171 which is the region above the heating unit shown as Fig. 1, is $500(\mathrm{~W}) \times 800(\mathrm{H}) \mathrm{mm}$. As shown as

172 Fig. 2 (a), the dimension of the view field is $280(\mathrm{~W}) \times 280 \mathrm{~mm}(\mathrm{H})$ and there are overlap areas

173 conductive to connecting the separate measurement domains. The six airflow fields are connected

174 using the technique stated in [32]. The relevant parameters of PIV system are shown in Table. 3.

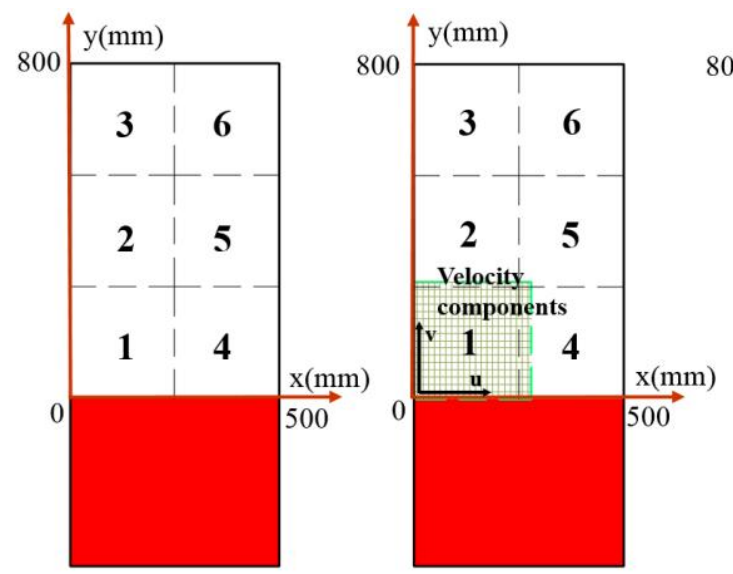

(a)

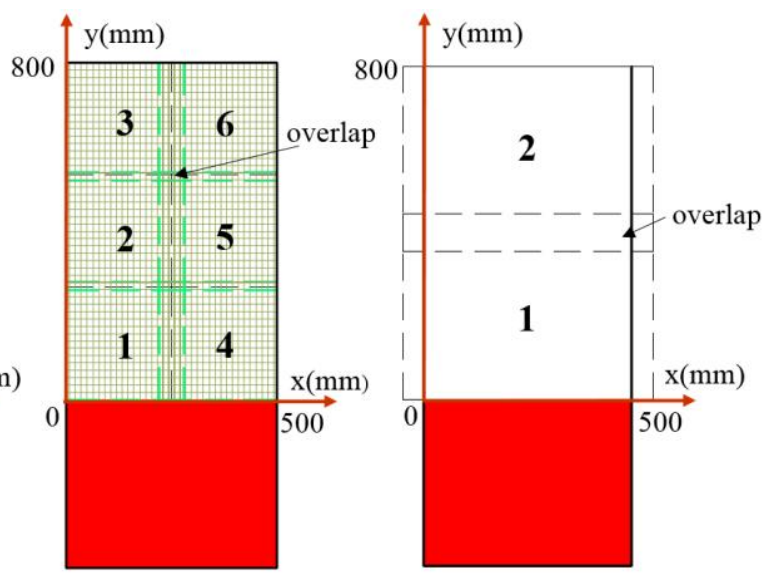

(b)

Fig. 2. Schematic of measurement domains a. PIV b. TIV

Table. 3. PIV parameters

\begin{tabular}{ll}
\hline Name & Parameters \\
\hline Laser model and power & Double-pulsed Nd:YAG laser, 150mJ/pulse \\
CCD model & PIVCAM13-8 \\
Lens model & AF Nikko 50mm f/1.8D Lens \\
Visual field of CCD & 2048 pixel $\times 2048$ pixel \\
Size of the interrogation window & 32 pixel $\times 32$ pixel, 50\% overlap \\
Dimension of the view field & $280(\mathrm{~W}) \times 280(\mathrm{H}) \mathrm{mm}$ \\
Spatial resolution & $0.137 \mathrm{~mm} /$ pixel \\
Sampling frequency & $7 \mathrm{~Hz}$ \\
Sampling pairs & 600 \\
\hline
\end{tabular}




\begin{tabular}{ll}
\hline Smoke generator & VZ09-0751 \\
\hline
\end{tabular}

178

180

\subsubsection{TIV measurement}

The accuracy of the measurement results cannot be guaranteed when the infrared camera captures the temperature fluctuations of the target surface through the Plexi-glass. In addition, the tracer particles suspended in space generate a considerable amount of scattering interference. Considering these two factors, the CCD camera and the infrared camera were positioned at the opposite sides. In this way, the measurement results of TIV are mirrored to make comparison with the results of PIV. In each shooting position, a circle hole fit for the camera lens was dug. The two holes were covered with lids to prevent the inner air from escaping. When conducting the TIV measurement, the lid was removed and the infrared camera captures the surface temperature of the observed Plexi-glass surface without the obstacles of any surfaces. The tiny space between the camera lens and the circle hole is sealed with cotton felt to stop the air leakage. Because the camera was placed and removed in a very short time and the shooting hole is very small, the amount of the gas entering or exiting the cavity at the moment of removal or resetting the lid can be negligible.

The surface temperature of the vertical wall was captured by a FLIR-T1040 infrared camera. Two .ats video files were acquired in two shooting positions located at $600 \mathrm{~mm}$ and $950 \mathrm{~mm}$ away from the bottom of the cavity. The entire visualized area is $500(\mathrm{~W}) \times 800(\mathrm{H}) \mathrm{mm}$ and decomposed into two domains and each domain area is $598(\mathrm{~W}) \times 445(\mathrm{H}) \mathrm{mm}$, shown as Fig.2 (b). The two airflow fields were connected with the method used in PIV. The detailed information of the parameters for thermal image velocimetry is shown as Table. 4.

Table. 4. Infrared camera parameters 


\begin{tabular}{ll}
\hline Name & Parameters \\
\hline Model & FLIR T1040 \\
Resolution & 1024 pixel $\times 768$ pixel \\
Sensitive wave length range & $7.5 \sim 14 \mu \mathrm{m}$ \\
noise-equivalent temperature difference & $25 \mathrm{mK}$ \\
Angel of version & $28^{\circ} \times 21^{\circ}$ \\
Dimension of the view field & $598(\mathrm{~W}) \times 445(\mathrm{H}) \mathrm{mm}$ \\
Spatial resolution & $0.584 \mathrm{~mm} / \mathrm{pixel}$ \\
Sampling frequency & $30 \mathrm{~Hz}$ \\
Sampling duration & $20 \mathrm{~s}$ \\
\hline
\end{tabular}

\subsubsection{Temperature measurement}

The temperature measurement was carried out using 32 RTDs. As placing so many RTDs in

201 the cavity may disturb airflow field, the temperature measurements and velocity measurements were carried out separately. The RTDs were calibrated by using a set of temperature calibration system. The RTDs were calibrated in the temperature range of 18 to $46{ }^{\circ} \mathrm{C}$, at fifteen points with an interval of $2{ }^{\circ} \mathrm{C}$. The linear calibration coefficients of the RTDs were acquired by regression analysis. The maximum error of the 33 RTDs was $0.347{ }^{\circ} \mathrm{C}$ before calibration. According to the linear correction of each RTD, the maximum error was decreased to $0.123{ }^{\circ} \mathrm{C}$. The temperature

207 measurement consists of two aspects. One is to investigate the temperature distributions inside the 208 cavity, shown as the dotted square labeled "1" in Fig. 3. The other aspect is to evaluate the inner 209 heat transfer of the vertical wall and the measurement points are shown in the dotted square labeled "2" in Fig. 3. 


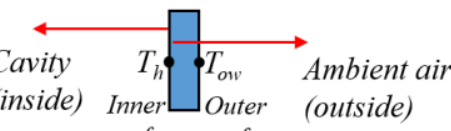

surface surface $T_{a}$
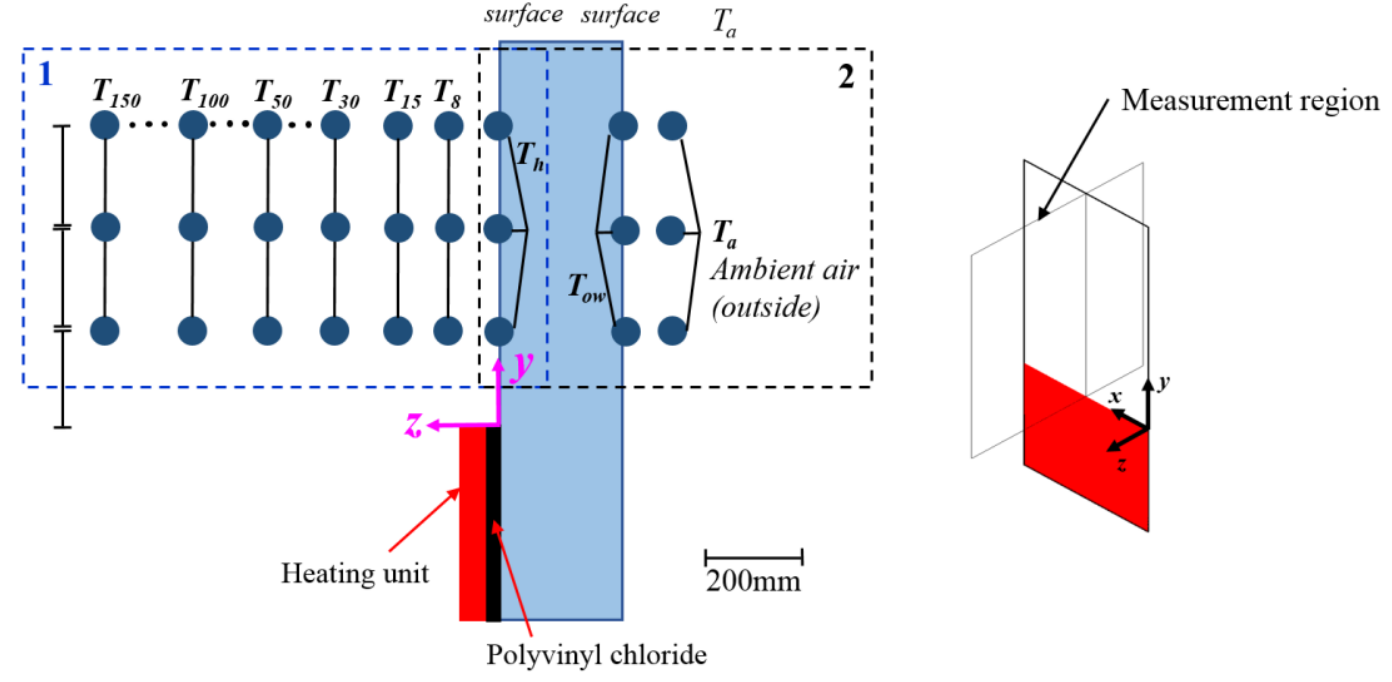

Fig. 3. Schematic distributions of temperature measurement points of the cavity

The heat transfer from the vertical wall can be obtained by the heat loss to the outside of the

cavity according to the energy balance of the vertical wall [33][34][35]. The calculation of heat

flux is based on stable conditions and the detailed calculation is as follows:

$$
q_{h}=\frac{T_{h}-T_{a}}{A_{w} R_{o}}
$$

Where $T_{h}(\mathrm{~K})$ is the temperature of inner vertical wall surface; $T_{a}(\mathrm{~K})$ is the temperature of the air

adjacent to the outer wall surface; and $A_{w}\left(\mathrm{~m}^{2}\right), R_{o}\left(\mathrm{~K} \cdot \mathrm{W}^{-1}\right)$ are the area of the vertical surface and the thermal resistance between the inner surface and the outer ambient air respectively. $R_{o}$ can be measured as:

$$
R_{o}=\frac{1}{\left(h_{o, \text { rad }}+h_{o, \text { con }}\right) A_{o}}+\frac{L_{w}}{\lambda_{w} A_{w}}
$$

where $A_{o}\left(\mathrm{~m}^{2}\right)$ is the area of the vertical wall that involves in heat exchange outside the cavity; $\lambda_{w}$ $\left(\mathrm{W} \cdot \mathrm{m}^{-1} \cdot \mathrm{K}^{-1}\right)$ and $L_{w}(\mathrm{~m})$ are the thermal conductivity and the height of the vertical surface; and $h_{o, r a d}\left(\mathrm{~W} \cdot \mathrm{m}^{-2} \cdot \mathrm{K}^{-1}\right), h_{o, c o n}\left(\mathrm{~W} \cdot \mathrm{m}^{-2} \cdot \mathrm{K}^{-1}\right)$ are the radiant and convection heat transfer coefficient of the 
outer vertical wall surface. Since the area of the outer wall surface is small enough with respect to the inner surface area of the entire air-conditioned room, the radiation heat transfer coefficient of the outer vertical wall surface can be calculated as:

$$
h_{o, \text { rad }}=\frac{\sigma \varepsilon_{o}\left(T_{o w}{ }^{4}-T_{c}^{4}\right)}{\left(T_{o w}-T_{c}\right)}
$$

where $\sigma\left(\mathrm{W} \cdot \mathrm{m}^{-2} \cdot \mathrm{K}^{-4}\right)$ is the Stefan-Boltzmann constant, $\varepsilon_{o}$ is the surface emissivity of the outer wall surface and is equal to $0.90, T_{o w}(\mathrm{~K})$ and $T_{c}(\mathrm{~K})$ are the temperature of outer vertical wall surface and the inner surface of the air-conditioned room.

The convection heat transfer coefficient can be manipulated as:

$$
h_{o, \mathrm{con}}=\frac{N u \lambda_{w}}{H_{w}}
$$

where $H_{w}(\mathrm{~m})$ is the height of the vertical wall that involves in heat exchange outside the cavity, $\mathrm{Nu}$ is the dimensionless parameter which is calculated using the correlation summarized in [36] based on the Rayleigh number.

The distributions of temperature points are shown as Fig. 3. Twenty-one RTDs were inserted at the following locations: $x=250 \mathrm{~mm}$ as shown as Fig.1, at heights of $200 \mathrm{~mm}, 400 \mathrm{~mm}, 600$ $\mathrm{mm}$ away from the upper level of the heating unit along $y$ axis, and at $0 \mathrm{~mm}, 8 \mathrm{~mm}, 15 \mathrm{~mm}, 30$ $\mathrm{mm}, 50 \mathrm{~mm}, 100 \mathrm{~mm}, 150 \mathrm{~mm}$ away from the vertical wall along the $z$ axis. Six RTDs were mounted at $x=250 \mathrm{~mm}$ and at heights ( $y$ direction) of $200 \mathrm{~mm}, 400 \mathrm{~mm}$, and $600 \mathrm{~mm}$; they were used to capture the outer vertical wall surface temperature and the temperature of the air adjacent to the outer surface. Four RTDs were used to measure the inner wall surface temperature of the air-conditioned room, and the temperature of the air-conditioned room was obtained by one RTD 
241 placed in the center of the room. The temperature series were stored in a computer by using the

242 Agilent 34980A multiplexer module. The sampling frequency was $0.1 \mathrm{~Hz}$, with a response time of $24310 \mathrm{~s}$.

\section{3. Results}

\subsection{Evaluation of temperature measurements}

\subsubsection{Temperature distributions}

Fig. 4 (a) - (c) show the temperature series of three cases in continuous time during the last one hour. In Fig. 4 (a), (b), (c), the three subfigures from left to right represent the temperature

249 series at the heights of $200 \mathrm{~mm}, 400 \mathrm{~mm}$ and $600 \mathrm{~mm}$. The temperature fluctuation near the

253 When mechanical ventilation is imposed, the near-wall air temperature and the temperature

254 fluctuation decreases.
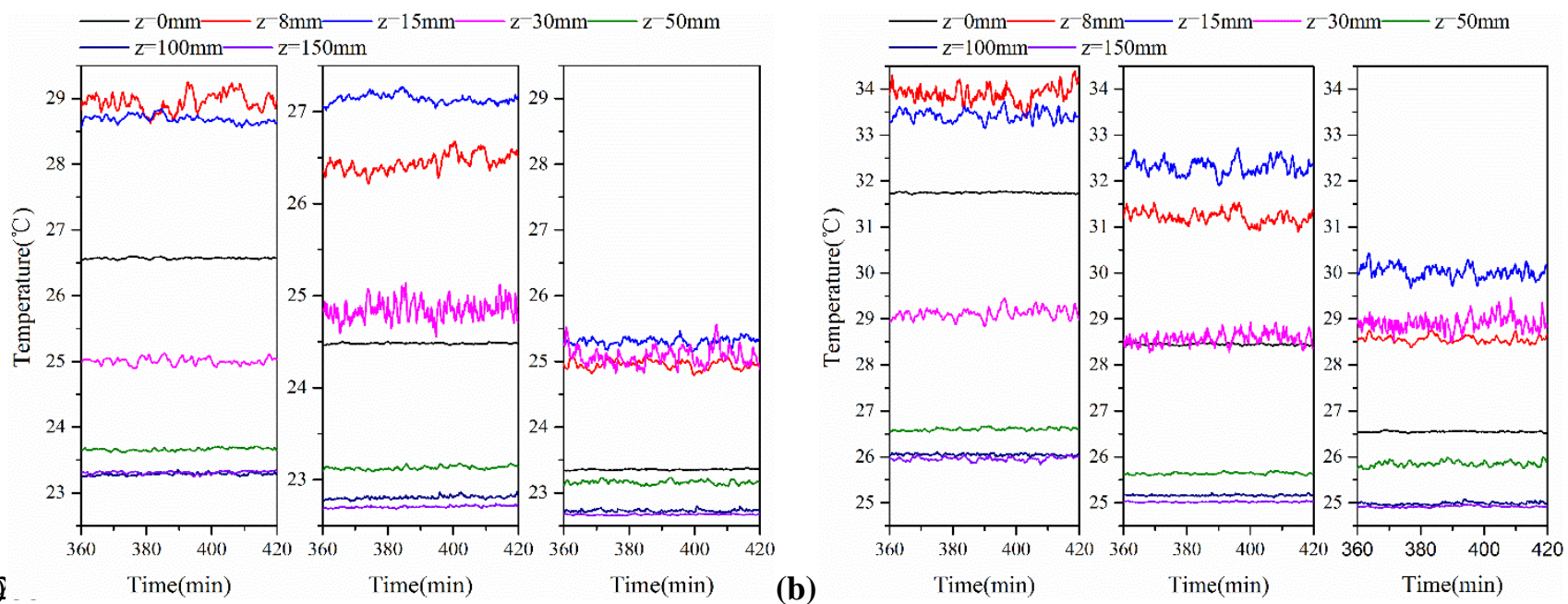


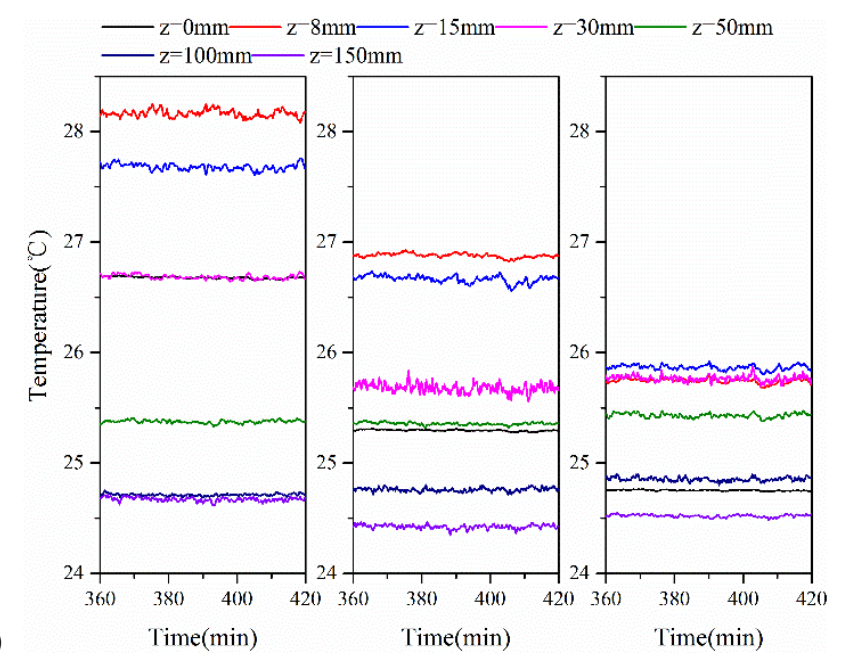

(c)

Fig. 4. Temperature series of the $y$-positions, $200 \mathrm{~mm}, 400 \mathrm{~mm}, 600 \mathrm{~mm}$ of the three cases (a) Case 1 (b) Case 2 (c) Case 3

show a similar distribution trend, which is an increase to a peak value and a gradual decrease. The temperature of the heating unit and the ventilation condition not only affect the temperature magnitude in the cavity, but also the temperature distribution characteristics. With an increase in heating temperature, the air temperature in space increases significantly. The gradient of the air temperature near the vertical surface increases dramatically as well. Under the effect of mechanical ventilation, the air temperature of Case 3 tends to be more uniform, and the temperature gradient near the vertical wall is largely weakened and approaches that of condition of Case 1, even though the heating temperature is higher.

As stated in [3][15], due to the insufficiency of the thermal buoyancy driving force, part of the hot airflow above the heat source deviates from the original flow direction. Due to flow detachment, the air temperature distribution also exhibits the same detachment [3]. The hot air flows upward for some distance until the buoyancy force is smaller than gravity and rushes to the inner regions of the cavity. At the height of $200 \mathrm{~mm}$ for all the cases, the air temperature increases to a maximum value in the plane that is $8 \mathrm{~mm}$ away from the vertical surface and then keeps 
decreasing. If no temperature detachment exists, the trends at the other heights should also follow the same law as that at the height of $200 \mathrm{~mm}$. However, in Case 1 and Case 2, the maximum air temperature occurs $15 \mathrm{~mm}$ away from the vertical surface at heights of $400 \mathrm{~mm}$ and $600 \mathrm{~mm}$. In consequence, there exists a temperature detachment. In Case 3, there also exists a temperature detachment according to the changing tendency. Unlike the other natural cases, the maximum temperature occurs in $8 \mathrm{~mm}$ away from the vertical surface at the heights of $200 \mathrm{~mm}$ and $400 \mathrm{~mm}$.

For the height of $600 \mathrm{~mm}$, the maximum air temperature occurs $15 \mathrm{~mm}$ away from the vertical wall.

The temperature detachment height rises to $600 \mathrm{~mm}$ under the effect of mechanical ventilation.

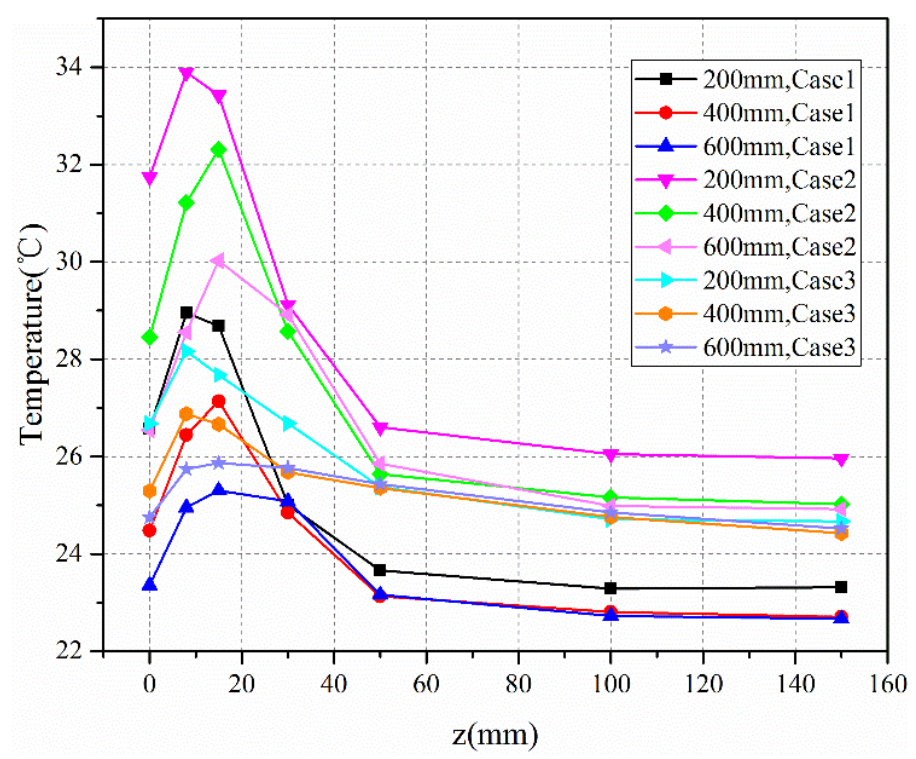

Fig. 5. The distribution of time-averaged temperature of three cases.

3.1.2 Heat transfer of the inner vertical wall

Based on the data processing method mentioned earlier, the inner heat transfer of the vertical wall was calculated and is shown in Fig. 6. Similar to the trend of the inner surface temperature, the heat flux of all the cases decreases with an increase in height. As the heating temperature increases, the inner surface temperature of the vertical wall increases, and the potential difference between the inner wall and the air outside the cavity increases; therefore, the heat loss to the outer 
Case 2, the heat flux of the inner wall is much smaller than that of Case 2.

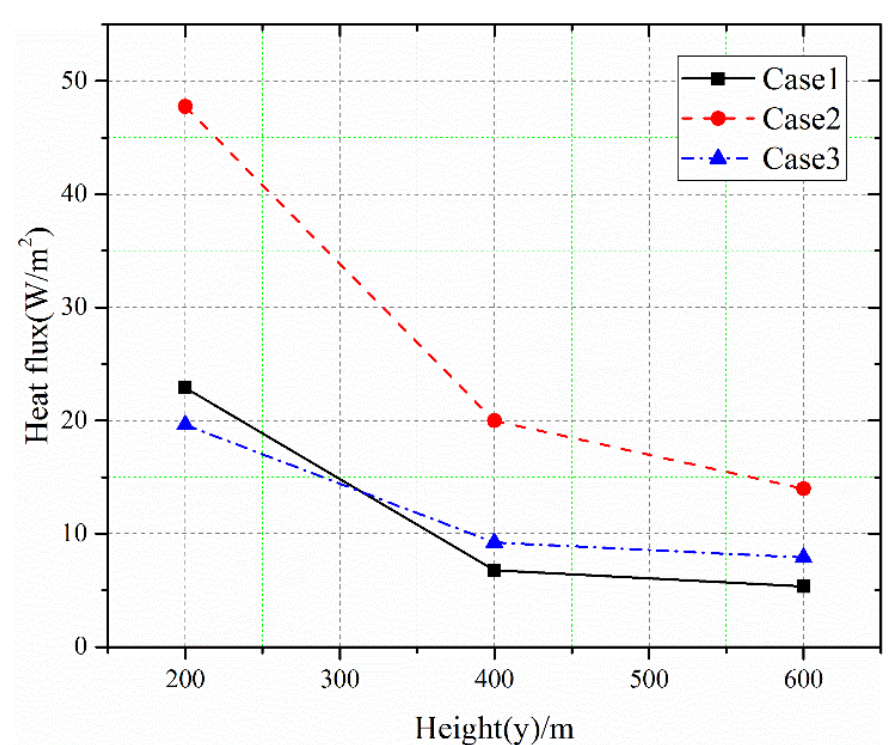

Fig. 6. The heat transfer of inner vertical wall

The energy balance of the vertical wall influences the heat transfer rate significantly. The schematic heat balance of the vertical wall is shown as Fig. 7(a). In steady state, the heat storage of the vertical wall is not taken into accountant. For the inner surface of the vertical wall, the heat transfer process includes the radiative and convective heat transfer in the cavity and the heat loss to the air adjacent to the outer wall. The radiative heat transfer rate of the inner wall is calculated by establishing the radiative heat transfer network [37]. The other five inner surfaces are viewed as a single surface since the temperature difference between each wall surface is not significant. The single surface, the heating unit and the vertical wall constitute a closed radiation heat transfer system. The surface thermal resistance is calculated by $R_{i}=\left(1-\varepsilon_{i}\right) /\left(A_{i} \varepsilon_{i}\right)$, where $\varepsilon$ is the surface emissivity, $A_{i}\left(\mathrm{~m}^{2}\right)$ is the surface area. The space thermal resistance is calculated by $R_{i j}=1 /\left(A_{i} X_{i j}\right)$, where $X_{i j}$ is the view factor from surface $i$ to surface $j$. Since the vertical wall and the heating unit are arranged in parallel, the view factor between the two surfaces is 0. According to heat balance, 
the convective heat transfer rate is the sum of the heat loss and the radiative heat transfer rate. The heat transfer rates of the three cases are shown are Fig. 7 (b)-(d). As shown in Fig.7, compared with the radiative heat transfer, the convective heat transfer occupies a large proportion and has a decisive role in the net heat flux of the vertical wall.

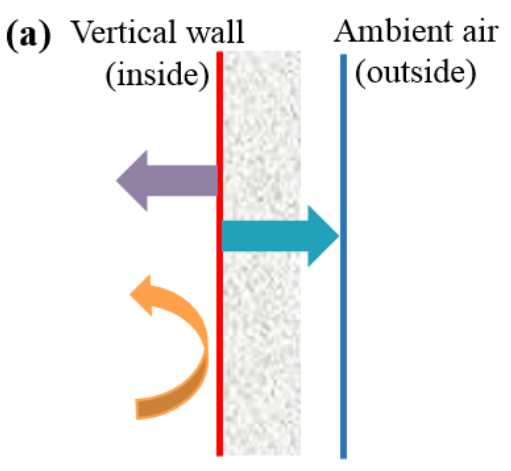

(c)

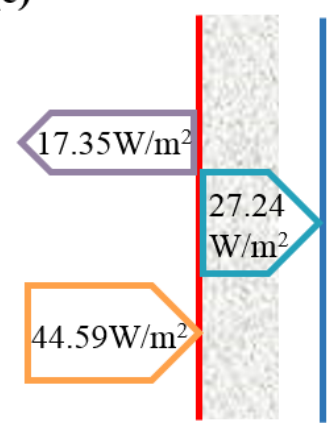

(b)

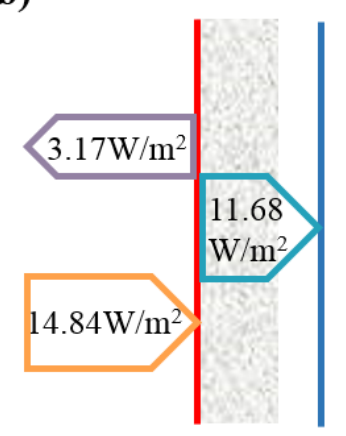

(d)

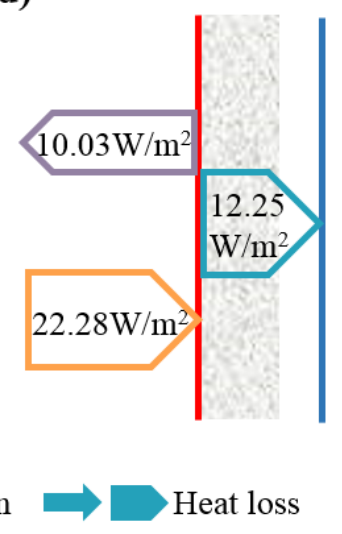

Fig. 7. (a) Schematic heat balance of the vertical wall, (b)-(d) detailed heat transfer rates of Case 1 to Case 3. evaluation of the air flow rate based on the PIV measurement results was made. In the thin layer near the wall, heat transfer occurs between the air and the wall and thus the air flow rate used to calculate the heat flux should be close to the wall. We used the velocities in the plane that is $8 \mathrm{~mm}$ away from the vertical wall to calculate the air flow rate. The velocities in the $8 \mathrm{~mm}$ plane are averaged and the spatial-averaged velocities of Case 1 to Case 3 are $0.22 \mathrm{~m} / \mathrm{s}, 0.27 \mathrm{~m} / \mathrm{s}$, and 
Therefore, in this study, the impact of the air flow rate is not significant compared with the other influencing factors.

The thickness of the thermal boundary layer is an essential factor to evaluate heat transfer. With the increase of heating temperature, the heat transfer efficiency is enhanced, and the thermal boundary layer of Case 2 should be thinner than that of Case 1. As a result, through comparing the thickness of the thermal boundary layer of Case 2 and Case 3, the relative heat transfer efficiency of natural convection and the mixed convection can be determined. In this study, the thickness of the thermal boundary layer of Case 2 and Case 3 in the height of $200 \mathrm{~mm}$ was compared. The Rayleigh number $\operatorname{Ra}\left(=g \beta\left(T_{s}-T_{\infty}\right) L^{3} \operatorname{Pr} / v^{2}\right)$ and the Reynolds number $\operatorname{Re}\left(=U L v^{-1}\right)$ of Case 2 and Case 3 are calculated, where $\beta\left(\mathrm{K}^{-1}\right)$ is the thermal expansion coefficient, $T_{s}(\mathrm{~K})$ is the surface temperature, $T_{\infty}(\mathrm{K})$ is the temperature of the mainstream and is regarded as the air temperature in the center of the cavity, and $L(\mathrm{~m})$ is the reference height of the vertical wall and is determined to be 0.2 . Through calculation, it is found that the boundaries of the two cases are laminar. For the case of isothermal vertical surface under natural convection, the thickness of the thermal boundary layer can be calculated as $\delta=5.3\left(\frac{g \beta\left(T_{s}-T_{\infty}\right)}{v^{2}}\right)^{-0.25} L^{0.25}$ [36]. In this study, the vertical wall is non-isothermal. If $T_{s}$ is taken as the temperature of the surface in the height of $200 \mathrm{~mm}$, the calculated thickness of the boundary later would be larger than the real value. In consequence, $T_{s}$ is taken as the average temperature of the surface in the region of $0-200 \mathrm{~mm}$. For the case of isothermal vertical surface under mixed convection, the thickness of the thermal boundary layer of the mixed convection can be calculated as $\delta=\frac{5 L}{\operatorname{Re}^{0.5}}[36]$. Then the thicknesses of the thermal boundary layers of Case 2 and Case 3 can be estimated to be $0.0125 \mathrm{~m}$ 
and $0.0066 \mathrm{~m}$. Therefore, the thickness of the thermal boundary layer of the natural convection cases are thicker than that of the mixed convection case. The change of heat flux is not consistent with the change of boundary layer, but presents an opposite trend.

However, as far as the experimental results in this study is concerned, the heat transfer cannot be only evaluated by the thickness of boundary layer. The thickness of the boundary layer is the combined effect of the flow and heat transfer. The basic factor that influencing the heat flux is the thermal and flow state of the air. In order to evaluate the factors contributing to the heat flux, the temperature and the velocity of the air should be inspected. In the previous response, we have analyzed the influence of the velocity and air flow rate. Next, the temperature difference between the near-wall air and the vertical wall is taken into accounted. Fig. 8 shows the temperature the other factors.

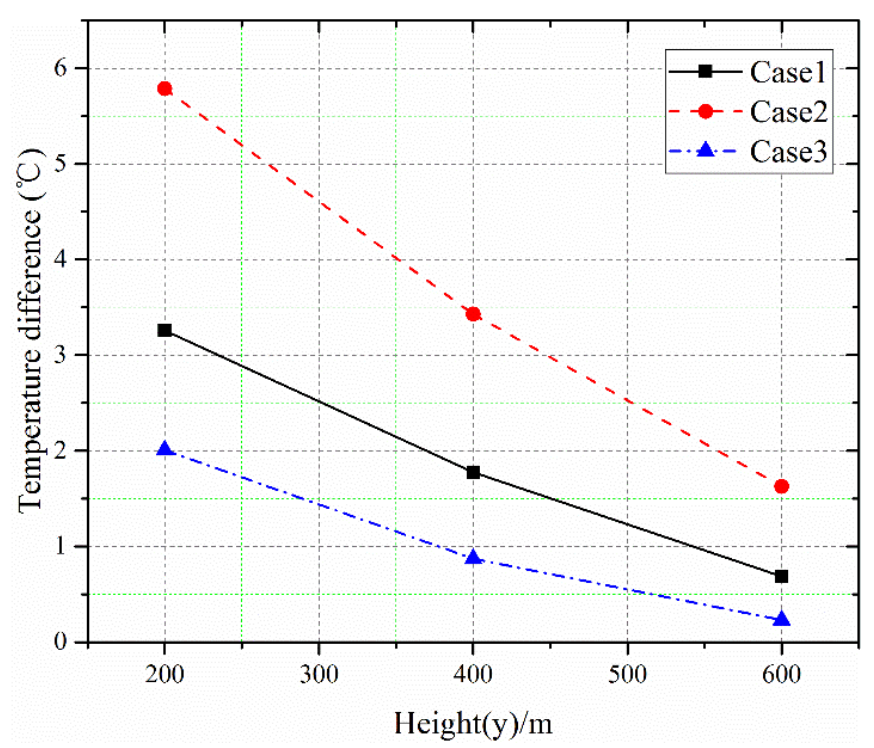


Fig. 8. The temperature difference between the vertical wall and air 100mm away from the vertical wall

Furtherly, since the heat is transferred from the near-wall air to the vertical wall, the temperature of the near-wall air is critical to the magnitude of the heat flux of the vertical wall. In natural convection case, the air is heated and circulated in the cavity and no air enters in the air duct. Under the effect of the fan, the near-wall air of Case 3 flows out of the cavity along the outlet positioned in the top of the cavity. In this study, the air duct is not insulated and its heat conductivity coefficient is evidently larger than that of the cavity. A huge amount of the heat obtained in the cavity is released from the air duct to the air-conditioned room. With the continuous heat release process, the inlet air temperature of Case 3 is lowered significantly. As a result, the heat flux of Case 3 is similar to that of Case 1 even though the heating temperature is $20^{\circ} \mathrm{C}$ higher.

\subsection{Evaluation of flow structures}

\subsubsection{Time averaged velocity distributions}

As mentioned previously, the two-dimensional velocity of the two planes that are $8 \mathrm{~mm}$ and $15 \mathrm{~mm}$ away from the vertical wall were measured by PIV. For the convenience of illustration, the velocities of the plane that were $8 \mathrm{~mm}$ and $15 \mathrm{~mm}$ away from the vertical wall that were measured by PIV are denoted as PIV8 and PIV15, respectively. The measured results of thermal image velocimetry are denoted as TIV. By averaging the instantaneous velocities, the time-averaged velocity fields measured by PIV and TIV under three cases can be obtained (Fig. 9 to Fig. 11).

Fig. 9 shows the time-averaged velocity filed of Case 1. From the perspective of the spatial distribution, the measured velocity shows vertical variation to some extent. As the height increases, 
the velocity gradually increases and reaches at maximum value at a height of $200 \mathrm{~mm}$. The velocity is maintained at a high level until the height increases to $400 \mathrm{~mm}$. As the height continues to increase, the velocity decreases gradually due to an insufficient buoyancy force. The distribution trend of Case 2 is similar to that of Case 1. However, due to an increase in heating temperature, the velocity distribution exhibits a more pronounced spatial difference in the vertical direction. In Case 2, the peak velocity appears at a height of 400-600 mm, which is higher than that of Case 1. Correspondingly, the maximum velocity value increases as well. Different from the distributions presented in Case 1 and Case 2, the velocity distributions of Case 3 show a decreasing trend with an increase in height. In Case 3, natural convection and mechanical ventilation have a synergistic effect on velocity distribution. As can be seen from Fig. 10, the influence of mechanical ventilation is stronger than that of natural convection and the velocity distribution characteristics are mainly determined by mechanical ventilation.

Further inspection of the relative magnitude of PIV15 and PIV8 shows that PIV15 is smaller than PIV8. The plume originates from the heating unit and rises to the upper quiescent region. As the perpendicular distance from the heating unit increases, the scale of the plume increases, eventually dissipating in the quiescent region owing to a decrease in buoyancy force caused by the cooling of cold air and viscous effects [36]. Due to an insufficient thermal buoyancy, the velocity decreases with an increase in perpendicular distance. As a result, the velocity in the plane that is $15 \mathrm{~mm}$ away from the vertical wall is lower than the velocity in the plane that is $8 \mathrm{~mm}$ away from the vertical wall. 


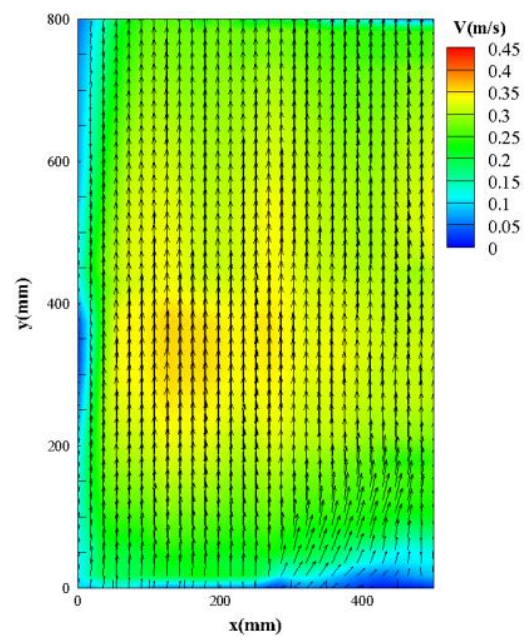

(a)

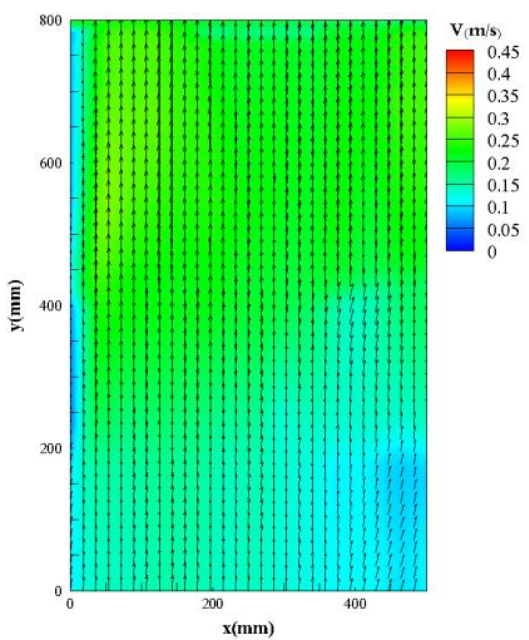

(b)

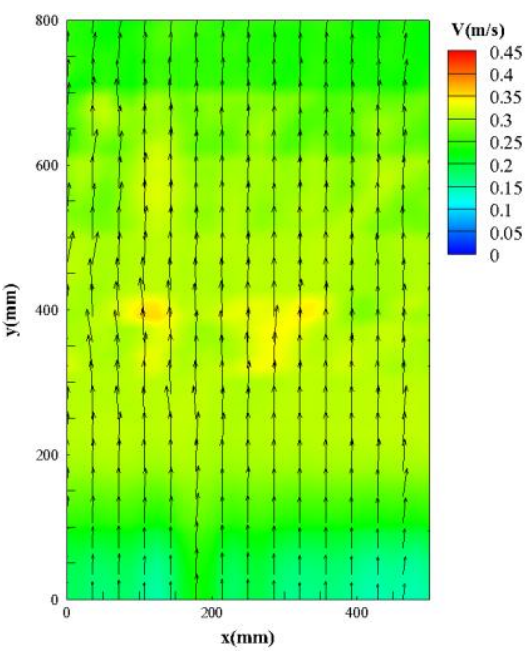

(c)

Fig. 9. Time-averaged velocity of Case 1, (a) PIV8, (b) PIV15, (c) TIV

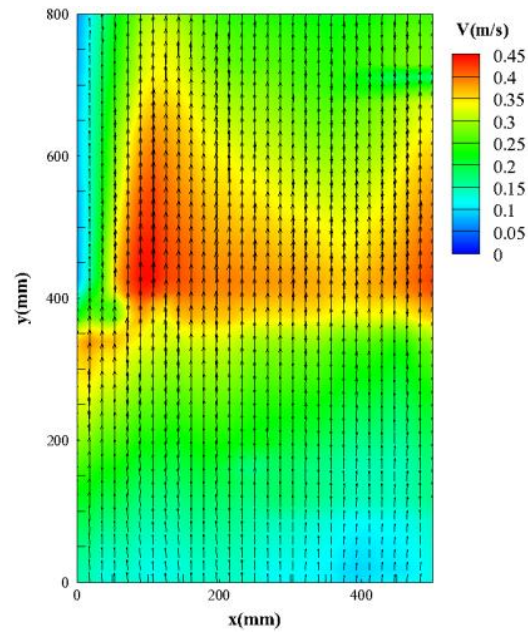

(a)

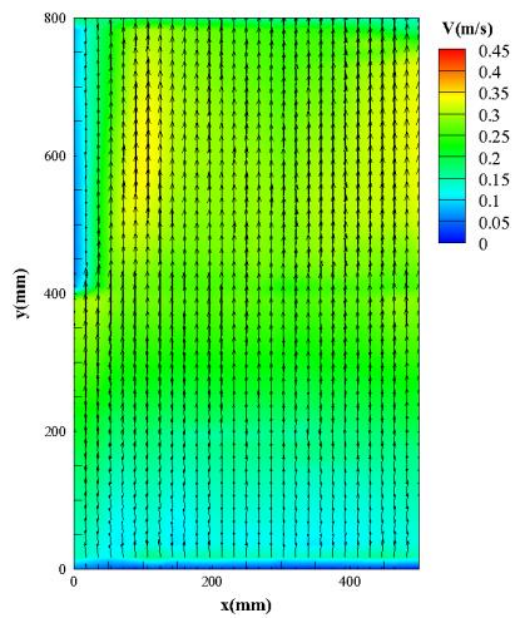

(b)

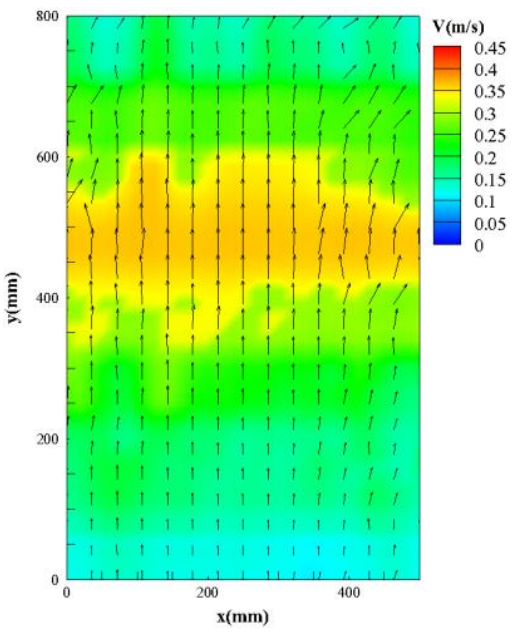

(c)

401

Fig. 10. Time-averaged velocity of Case 2, (a) PIV8, (b) PIV15, (c) TIV

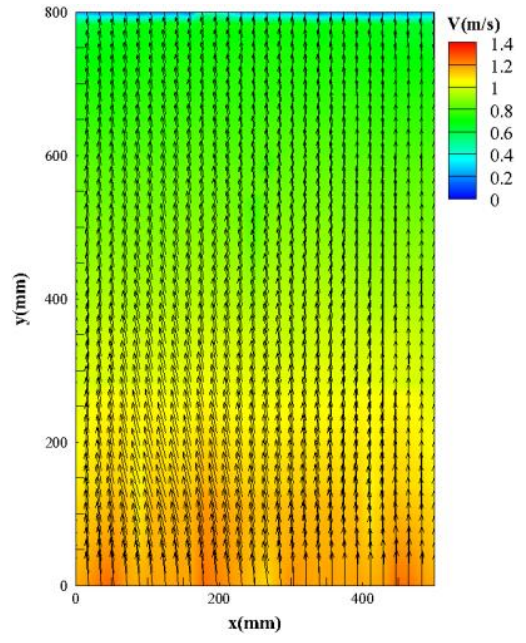

(a)

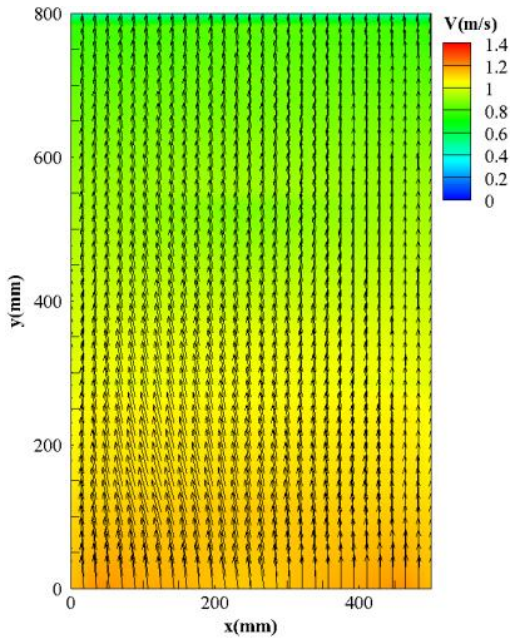

(b)

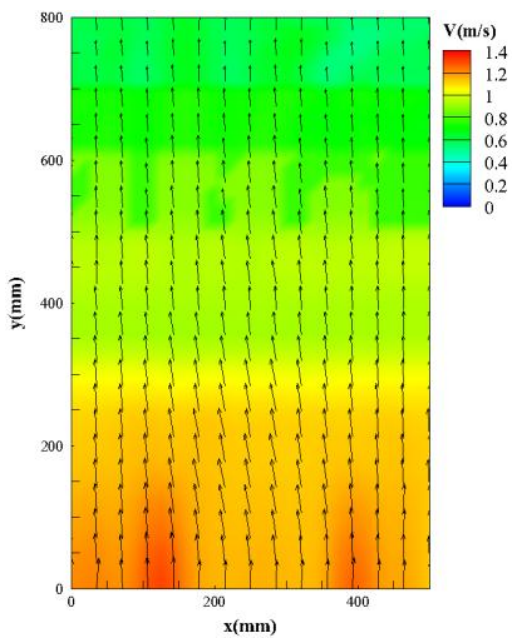

(c)

Fig. 11. Time-averaged velocity of Case 3, (a) PIV8, (b) PIV15, (c) TIV 

especially the measurement results of PIV8. However, in the three Cases, differences between TIV and PIV8 can be observed. The differences are directly related to the difference in measurement method principles. In the interaction between the wall surface and flow structures, heat is exchanged with the ejections and sweep of intermittent eddies. An essential factor that used to evaluate the heat transfer is the thickness of the boundary layer. As the heating temperature increases or mechanical ventilation is imposed, the thickness of boundary layer becomes thinner and the heat transfer is more intense. In TIV, the velocity is obtained by detecting the fluctuations of surface thermal spots. The temperature pattern captured by the infrared camera is closely related to the boundary layer [38]. As the thickness of the boundary layer changes, the "position" of the flow field measured by TIV changes accordingly. However, in the PIV experiment, the flow field of the planes that are $8 \mathrm{~mm}$ and $15 \mathrm{~mm}$ away from the vertical surface were measured, and thus, the measurement position is always fixed. With the change in the thickness of the boundary layer, the relative positions of PIV8 and TIV changes, and thus, the measurement results of TIV and PIV8 exhibit a certain difference in the three cases. more consistent in magnitude and trend. The position where the maximum velocity occurs and the magnitude of velocity can be accurately interpreted by TIV. Therefore, TIV has a certain

421 feasibility in reflecting the spatial distribution characteristics of the near-wall airflow. 
for a larger proportion than that in the TIV for the three cases. This is because that there exists a

lag between the surface temperature fluctuation and the near-wall velocity fluctuation. When the near-wall airflow changes, the surface shows the trace of the airflow in the form of surface temperature fluctuations. However, due to the heat storage of the vertical wall, the surface temperature cannot change immediately when the near-wall flow changes. As a result, the surface temperature fluctuations are weaker than those in the ideal situation, and the TIV measurement results tend to be distributed in the low velocity range.
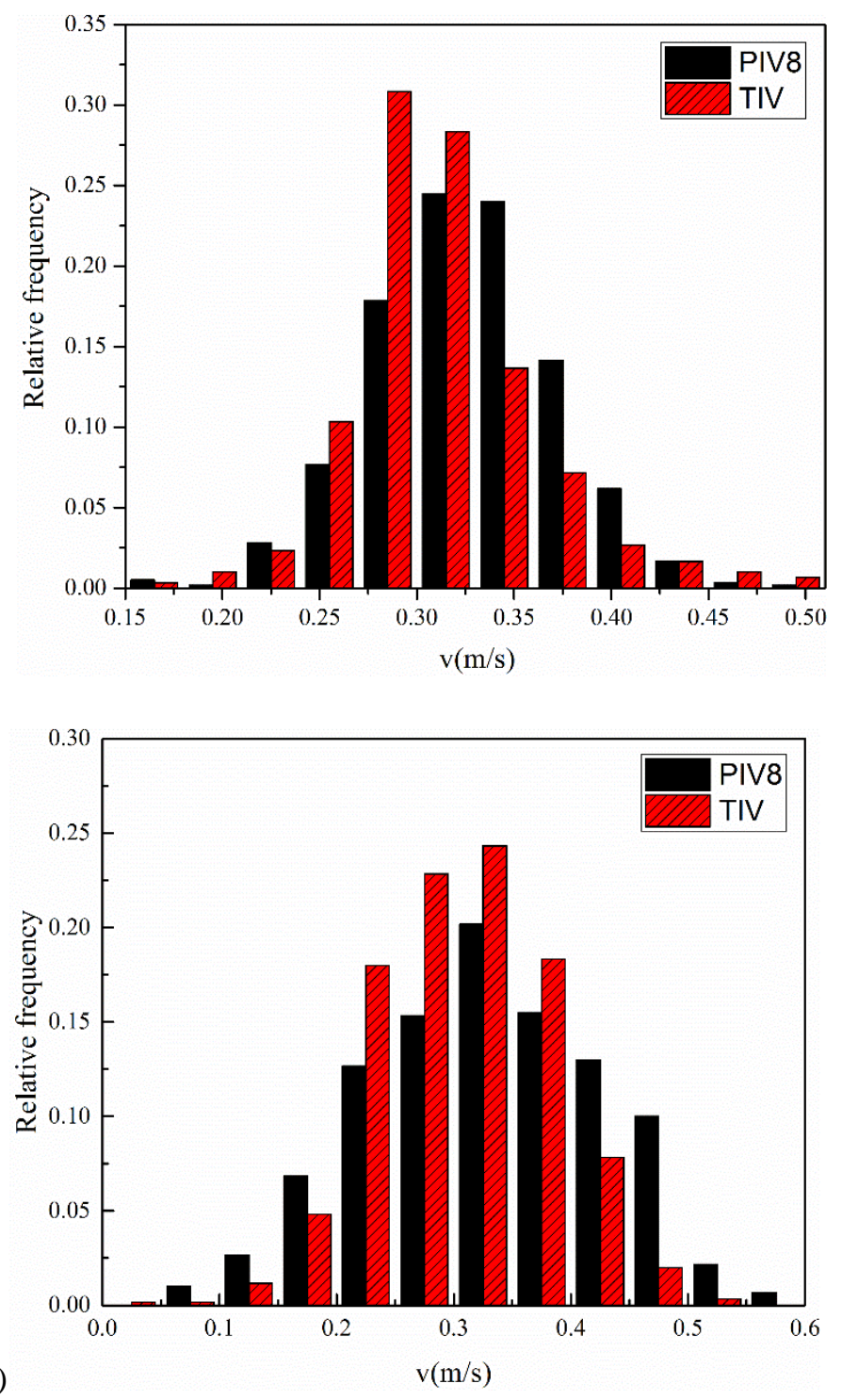


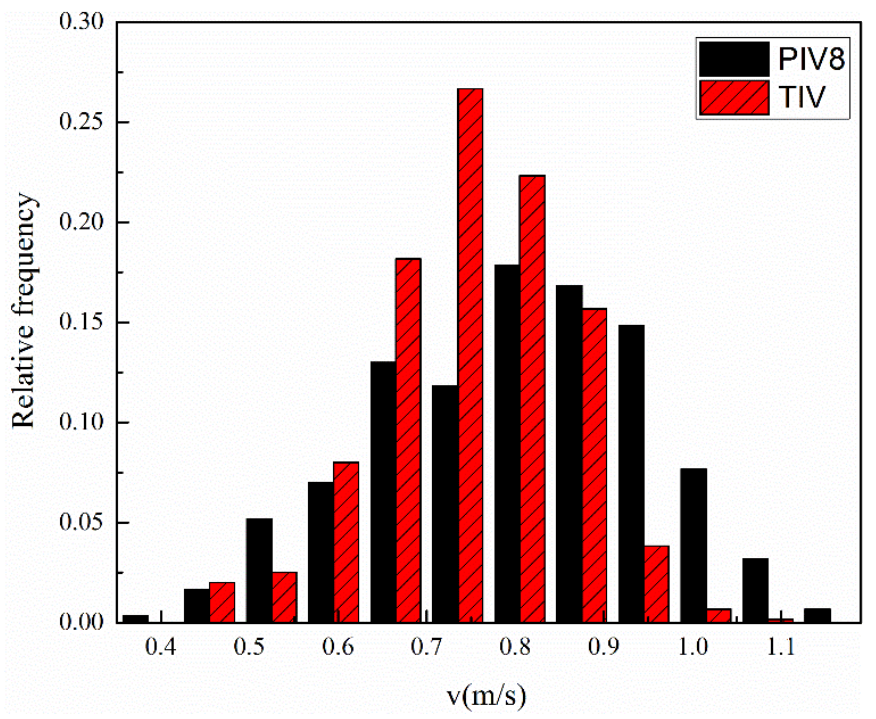

Fig. 12. The histograms of velocity at $x=250 \mathrm{~mm}, y=200 \mathrm{~mm}$, (a) Case1, (b) Case 2, (c) Case 3

\subsubsection{Power spectrum analysis}

The power spectrum analysis of the airflow fluctuation can be used to reveal the energy distributions in a frequency range and characterize the turbulent airflow [39]. The fluctuating velocity $\left(v^{\prime}\right)$ is obtained by subtracting the instantaneous velocity from the time-averaged velocity.

Based on the velocity fluctuation, the power spectrum density function can be defined as follows:

$$
\int_{0}^{\infty} E(f) d f=\overline{v^{\prime 2}}
$$

441 where $\mathrm{E}(f)\left(\mathrm{m}^{2} / \mathrm{s}\right)$ is the power spectrum density function, $f$ is the frequency $(\mathrm{Hz})$.

442 (a)
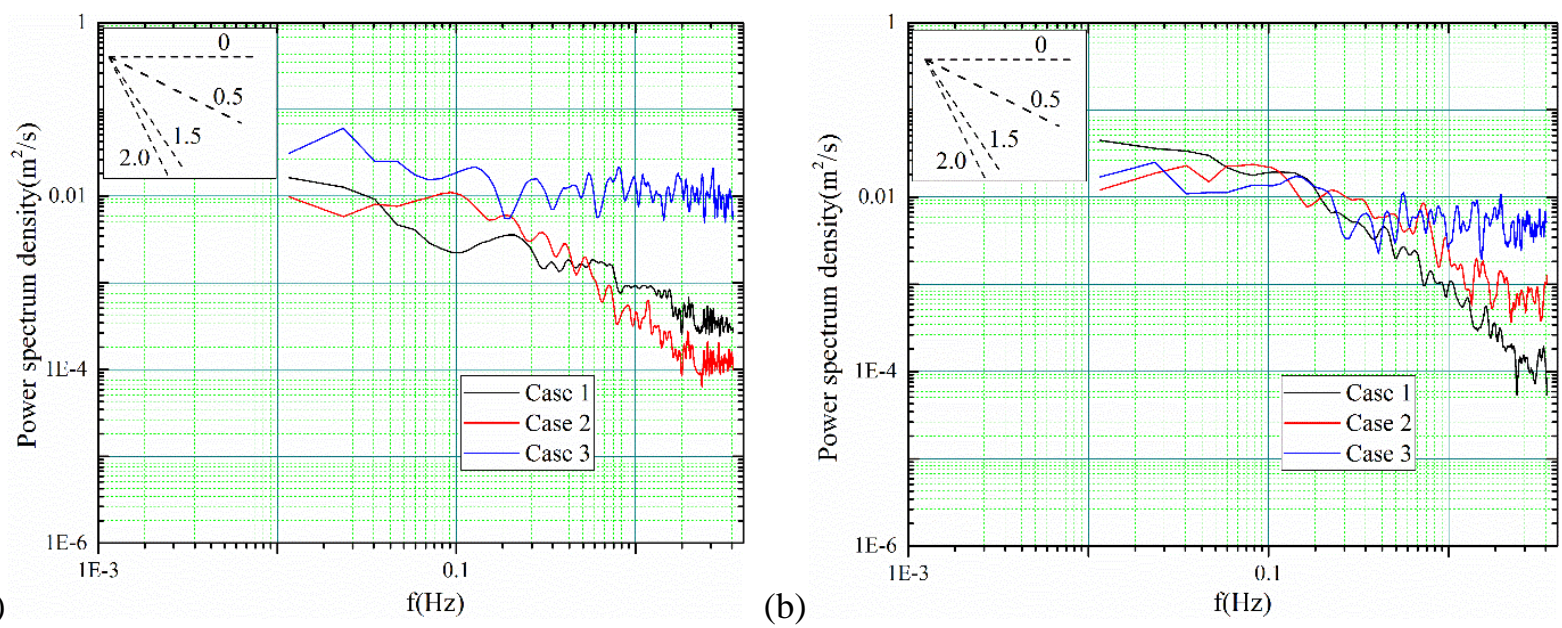

(b)

Fig. 13. Power spectra (a) at the height of $200 \mathrm{~mm}$; (b) at the height of $600 \mathrm{~mm}$

Fig. 13. (a) and (b) show the power spectrum density measured by PIV at the heights of 200 
$\mathrm{mm}$ and $600 \mathrm{~mm}$, respectively. The spectrum distributions of the velocity fluctuation of the three cases show a similar tendency, but there are still some differences in the inertial subrange. The negative slope of the logarithmic power spectrum curve of natural convection are between 1.5-2.0, while the negative slope of the mixed convection case is within $0-0.5$. This phenomenon was also observed by [40]. The negative slope of the inertial subrange in natural convection are close to $5 / 3$, showing that the flows are fully developed. The turbulence of Case 3 differs from that in the other cases, as it is influenced by the jet at the bottom of the cavity. With the diffusion of the jet airflow in the cavity, the average velocity decreased slightly, and the turbulence decreased slightly accordingly. velocity and the wave number, which can be used to show the contribution of different wave number on kinetic energy. The pre-multiplied velocity spectra at $x=250 \mathrm{~mm}, y=200 \mathrm{~mm}$ of TIV and PIV8 of the three cases are shown as Fig. 14.
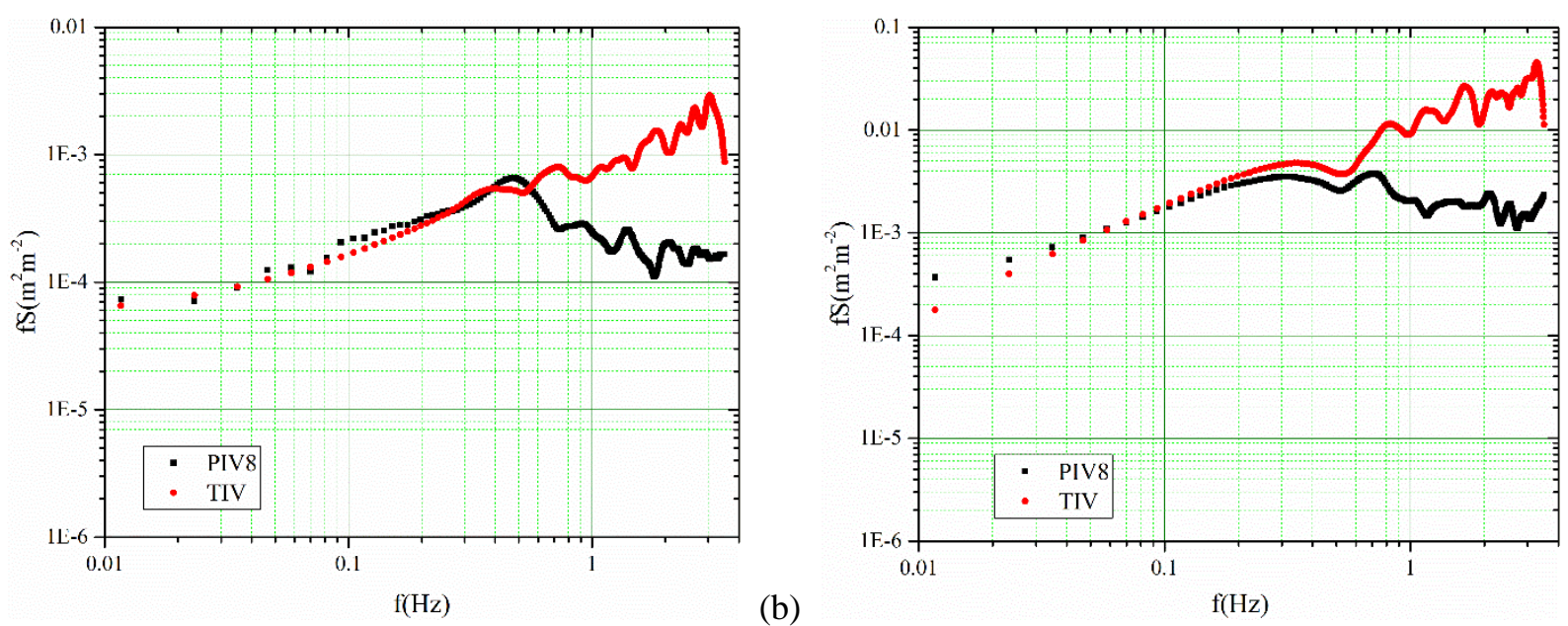


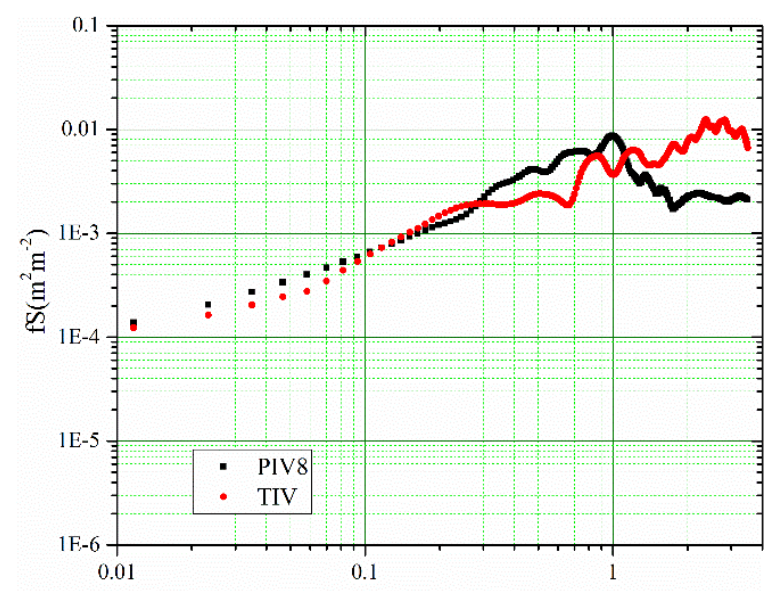

(c)

$$
\mathrm{f}(\mathrm{Hz})
$$

Fig. 14. Pre-multiplied power spectra of (a) Case 1, (b) Case 2, (c) Case 3

As can be seen from Fig. 14, the spectral shapes of the three cases all fit well in the low-frequency regions. As stated in [41], the turbulent flow consists of large scale and small scale structures. The large scale structures fluctuate with low frequency and represent the main motion of turbulent flow. The small scale structures are distributed in the high-frequency region and are advected by large scale structures. The great fitness in the low-frequency region means that the measurement results of TIV can reflect the main flow characteristics of turbulent flow motion. In the higher frequency regions, the spectral curves separate and the pre-multiplied power spectrum of TIV is more energetic than PIV, which is also observed in [25]. Due to the wall shear stresses, the closer to the wall, the more energetic the flow fluctuation is. The peak of the pre-multiplied spectra appears in the higher frequency region, which means that the airflow field evaluated by TIV may be closer to the vertical wall than the airflow field measured by PIV.

\section{Discussion}

In the foregoing section, we mentioned that the measurement results of TIV are influenced by the boundary layer. By analyzing the pre-multiplied spectrum of PIV and TIV, it is deduced that 
of the fixed plane measured by PIV. Although the measurement position of TIV cannot be directly determined, the dynamic characteristics of the PIV and TIV measurements provide a new perspective for estimating the information of the near-wall airflow field. We attempted to indirectly judge whether the result of the TIV measurement is affected by the boundary layer by judging the relative position of the two airflow fields measured by PIV and TIV and the boundary layer.

From the perspective of physical structure, turbulent flow can be regarded as a superposition of vortices with various sizes. Large scale vortices fluctuate with low frequency and extract energy from the mainstream. Through the interaction of vortices, energy is gradually transferred to the small-scale vortices which fluctuate with high frequency. Finally, due to fluid viscosity, small scale vortices disappear and the mechanical energy is converted into thermal energy of the fluid. The spectrum of temperature can be calculated as follows:

$$
E_{\theta}=\int_{0}^{\infty} E_{\theta}(\mathrm{k}) d k
$$

where $E_{\theta}$ is the power spectrum density function of temperature, $k$ is the wave number.

The exponential slope of the region between the flat low-frequency and the sharp drop at the high frequency represents the efficiency of energy transformation from the large scale to the small scale structures. In Zhang' study [42], it was found that the efficiency of energy transformation near the vertical surface varies greatly and reaches a maximum value near the boundary layer. Outside the boundary layer, the energy transformation efficiency almost remains constant with a constant exponent. As a result, it appears that the efficiency of the transformation from the large scale structure to the small scale structures can be used to estimate the position of the boundary layer. Based on this characteristic, we measured the temperature fluctuation of the air near the 
vertical surface and explored the slope of the power law distribution region.

An appropriate temperature sampling frequency is required to obtain the real-time information about the temperature field. However, due to the limitations of the measurement instrument, the sampling frequency is always restricted. The Kolmogorov time scale is used to evaluate whether the measurement frequency is sufficient. The Kolmogorov time scale can be calculated as: $\tau=(v / \varepsilon)^{0.5}, \varepsilon=U^{3} / H$, where $\nu$ is the turbulent viscosity, $\varepsilon$ is the turbulent dissipation rate, $U$ is root mean square velocity, $H$ is the turbulence length scale. In this study, the Kolmogorov time scale is $0.245 \mathrm{~s}$ for Case 1 . The temperature fluctuations were collected by Angilent $34980 \mathrm{~A}$ with a frequency of $7 \mathrm{~Hz}$. The response time is $0.143 \mathrm{~s}$, which is smaller than the Kolmogorov time scale for Case 1 . In consequence, the data collected at $7 \mathrm{~Hz}$ can be used to evaluate the energy transformation efficiency.

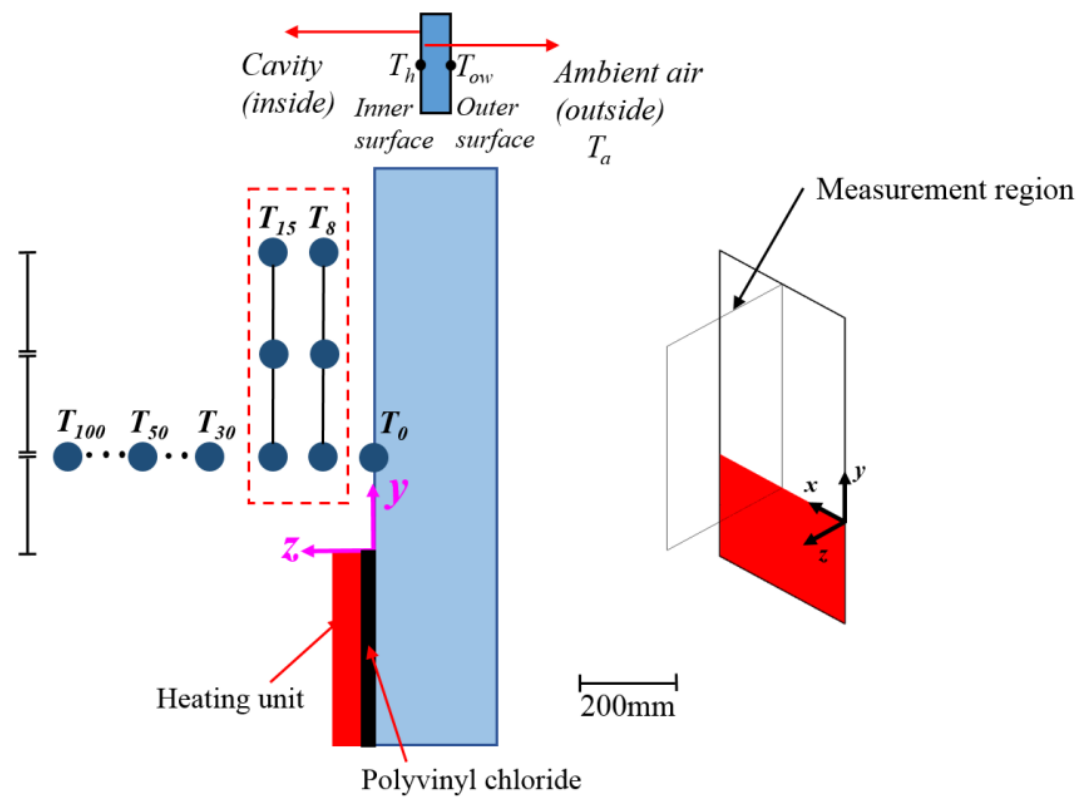

Fig. 15. Schematic distribution of temperature measurement points

As shown in Fig. 15, the temperature fluctuations of the ten points were measured. The power spectrum distributions of the six points in the planes that are $8 \mathrm{~mm}$ and $15 \mathrm{~mm}$ away from the vertical surface are shown in Fig. 16. The six points have the same arrangement as the former 
temperature measurement arrangement. The power spectrum distributions of the other four points located at the height of $200 \mathrm{~mm}$, and are $0 \mathrm{~mm}, 30 \mathrm{~mm}, 50 \mathrm{~mm}, 100 \mathrm{~mm}$ away from the vertical surface are presented in Fig. 17. The line are fitted in the power law distribution region and the slopes are shown in figures.

For the plane that is $8 \mathrm{~mm}$ away from the vertical surface, energy transfer efficiency decreases with an increase in height. As for the plane that is $15 \mathrm{~mm}$ away from the vertical surface, heat transfer efficiency is almost constant and is smaller than that for the plane that is $8 \mathrm{~mm}$ away from the vertical surface. Combining Fig. 16 and Fig. 17, it can be found that the energy transformation efficiency increases from $0 \mathrm{~mm}$ to $8 \mathrm{~mm}$. The efficiency decreases from $8 \mathrm{~mm}$ to $15 \mathrm{~mm}$ and remains almost constant within $15 \mathrm{~mm}$ to $30 \mathrm{~mm}$ from the vertical surface. When the distance is increased to $50 \mathrm{~mm}$, the efficiency decreases greatly. When distance increases and for to the regions far away from the vertical surface, the efficiency reduces due to a small temperature gradient and weak convection. According to the aforementioned analysis, the efficiency increased to its maximum value near the boundary layer and remains almost constant outside the boundary layer. It can, therefore, be deduced that the plane that is $8 \mathrm{~mm}$ away from the vertical surface is near the boundary layer, and the plane that is $15 \mathrm{~mm}$ away from the vertical surface is outside the boundary layer. In combination with the fact that the TIV velocity is close to that of PIV8, it can be identified that the velocity plane measured by TIV is also near the boundary layer. Although unable to establish a direct relation, it is ascertained that the measured results of TIV can reflect the dynamic characteristics of the near-wall region in either natural or mixed convection. 

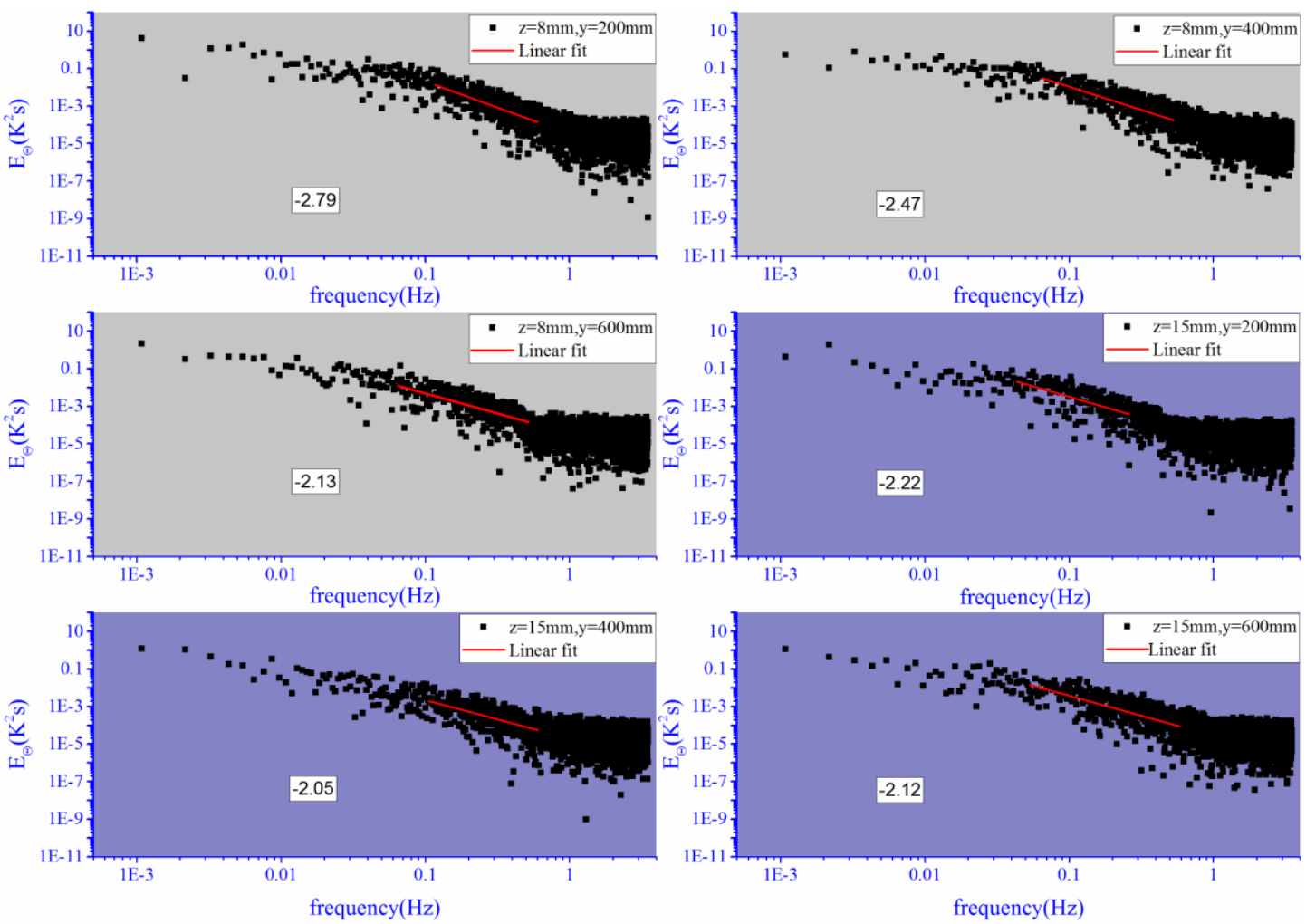

Fig. 16. Power spectrum of temperature of the points in the plane of $8 \mathrm{~mm}$ and $15 \mathrm{~mm}$ away from the

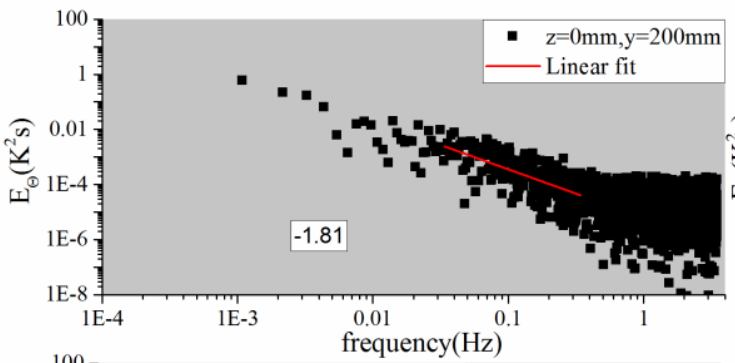
vertical surface
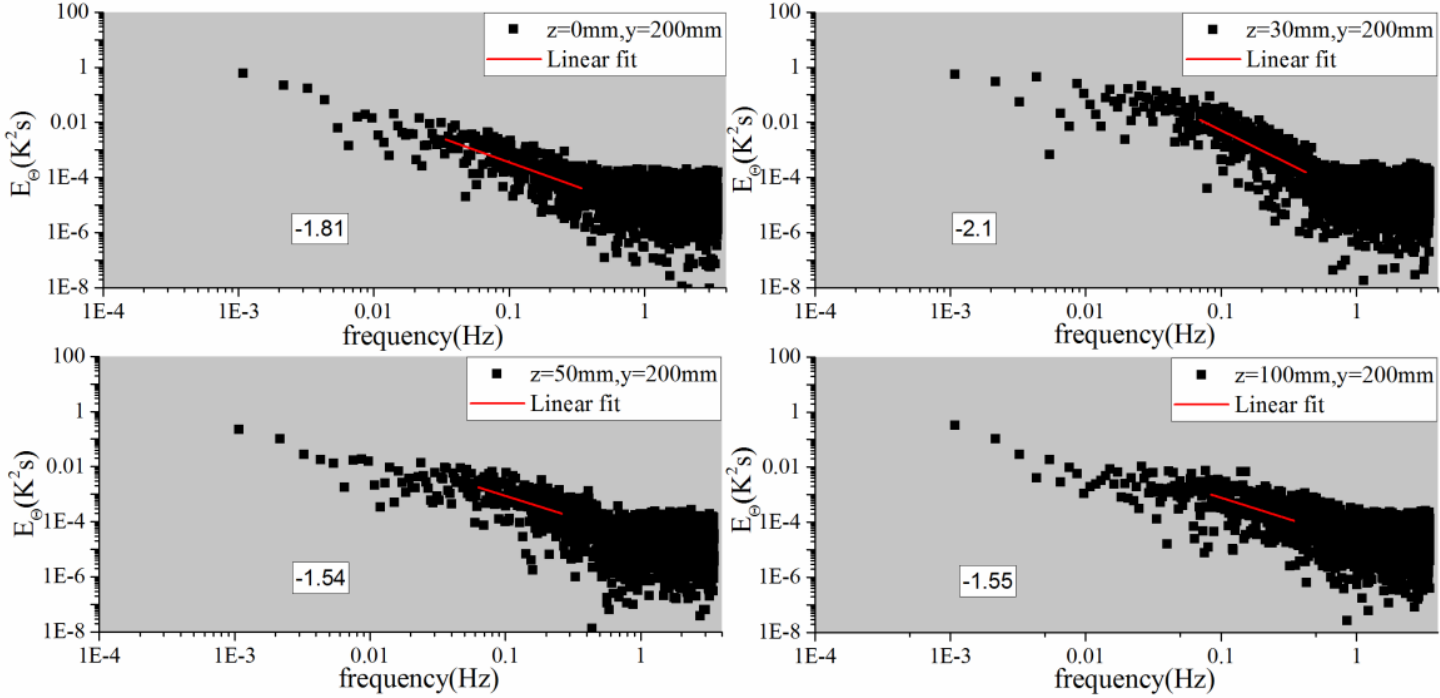

Fig. 17. Power spectrum of temperature of the points that are $0 \mathrm{~mm}, 30 \mathrm{~mm}, 50 \mathrm{~mm}$ and $100 \mathrm{~mm}$ away from the vertical surface

Although the dimension and shape of the heating unit in this study are somewhat different

from those of actual radiator, the heat transfer process of the heating unit is similar to that of an

actual radiator under full scale room conditions. The influence of the surface temperature of the

heating unit and the mechanical ventilation on the thermodynamic state of the near-wall airflow 
over the heating unit found in this study can be referred in the research of actual heating room. In addition, TIV is proved to be feasible in the measurement of the near-wall airflow over a heating unit and can be used as an alternative indoor velocity measurement method to make up for the fact that it is difficult to use PIV in full scale measurements. Based on the measurement and analyzing method, future work can be carried out to investigate the thermodynamic state of the airflow over a radiator in a full scale room environment.

\section{Conclusions}

This paper analyzed the thermodynamic state of the near-wall airflow over an idealized heating unit. The air temperature was measured by RTDs, and the near-wall velocity distributions were measured by the PIV method and TIV method. By analyzing the temperature and velocity measurement results, the following conclusions can be drawn:

(a) Overall, TIV and PIV8 are close and consistent in magnitude and trend. TIV has certain feasibility in reflecting the spatial distribution characteristics of the near-wall airflow in both natural convection and mixed convection. The spectral shapes of TIV and PIV fit well in low-frequency regions. The great fitness in the low-frequency region means that the measurement results of TIV can reflect the main flow characteristics of turbulent flow motion. TIV can be used to obtain the near-wall velocity according to the wall surface temperature fluctuations and the obtained velocity is closely associated with the boundary layer. Due to the heat storage of the vertical wall, lag exists between the surface temperature fluctuation and the near-wall velocity fluctuation.

(b) Influenced by thermal buoyancy, the near-wall velocity over the heating unit in natural 
convection case shows vertical variation. With an increase in heating temperature, the velocity distribution exhibits a more pronounced spatial difference in the vertical direction, and the position at which the maximum velocity occurs moves upward. Correspondingly, the value of the maximum velocity increases with an increase in heating temperature as well. The flow under natural convection cases is in fully developed turbulent, and the flow state of mixed convection is influenced by the characteristics of supply air. The influence of mechanical ventilation is far stronger than that of natural convection in mixed convection case, and as the vertical distance from the air inlet increases, the air velocity gradually decreases.

(c) The temperature fluctuation near the vertical surface is large at locations within $30 \mathrm{~mm}$ away from the vertical surface. The temperature of the air near the vertical wall has a significant influence on the heat transfer rate of the vertical wall. With an increase in heating temperature, the air and surface temperature gradients increase, especially those near the vertical surface. Accordingly, the near-wall heat transfer rate of the vertical wall increases as well. Under the effect of mechanical ventilation, the air and surface temperatures decrease and tend to be more uniform, and the temperature gradient is reduced. The heat transfer rate of the vertical wall decreases. Due to an insufficient of driving force, there exists a temperature detachment over the heating unit. Influenced by mechanical ventilation, the detachment position of the mixed convection case is higher 
commercial, or not-for-profit sectors.

\section{References}

[1] J.A. Myhren, S. Holmberg, Performance evaluation of ventilation radiators, Appl. Therm. Eng. 51 (2013) 315-324. doi:10.1016/j.applthermaleng.2012.08.030.

[2] J.A. Myhren, S. Holmberg, Design considerations with ventilation-radiators: Comparisons to traditional two-panel radiators, 41 (2009) 92-100. doi:10.1016/j.enbuild.2008.07.014.

[3] G. Sevilgen, M. Kilic, Numerical analysis of air flow, heat transfer, moisture transport and thermal comfort in a room heated by two-panel radiators, 43 (2011) 137-146. doi:10.1016/j.enbuild.2010.08.034.

[4] A. Jahanbin, E. Zanchini, Effects of position and temperature-gradient direction on the performance of a thin plane radiator, Appl. Therm. Eng. 105 (2016) 467-473. doi:10.1016/j.applthermaleng.2016.03.018.

[5] W. Zhao, Y. Hu, Y. Wang, W. Qin, Thermal performance of a suspended ceiling fi $n$ heat transfer panel with drain pan, Build. Environ. 144 (2018) 622-630. doi:10.1016/j.buildenv.2018.09.004.

[6] Y. Lyu, X. Wu, C. Li, H. Su, L. He, Numerical analysis on the effectiveness of warm water supply in water flow window for room heating, Sol. Energy. 177 (2019) 347-354. doi:10.1016/j.solener.2018.11.033.

[7] S. Xu, R. Ding, J. Niu, G. Ma, Investigation of air-source heat pump using heat pipes as heat radiator, Int. J. Refrig. 90 (2018) 91-98. doi:10.1016/j.ijrefrig.2018.03.025.

[8] H.B. Awbi, A. Hatton, Natural convection from heated room surfaces, Energy Build. 30 (1999) 233-244.

[9] T. Cholewa, R. Anasiewicz, A. Siuta-Olcha, M.A. Skwarczynski, On the heat transfer coefficients between heated/cooled radiant ceiling and room, Appl. Therm. Eng. 117 (2017) 76-84. doi:10.1016/j.applthermaleng.2017.02.019.

[10] Y. Sun, Y. Zhang, An Overview of Room Air Motion Measurement: Technology and Application, HVAC\&R Res. 13 (2007) 929-950. doi:10.1080/10789669.2007.10391463.

[11] S. Fu, P.H. Biwole, C. Mathis, Particle tracking velocimetry for indoor airflow field: A review, Build. Environ. 87 (2015) 34-44. doi:10.1016/j.buildenv.2015.01.014.

[12] C. Cierpka, R. Hain, N.A. Buchmann, Flow visualization by mobile phone cameras, Exp. Fluids. 57 (2016). doi:10.1007/s00348-016-2192-y.

[13] A. Sattari, Particle image velocimetry visualization and measurement of airflow over a wall-mounted radiator, Int. J. Vent. 14 (2015) 289-302. doi:10.1080/14733315.2015.11684087.

[14] W. Du, Y. Liu, H. Yuan, S. Qiao, S. Tan, Experimental investigation on natural convection and thermal stratification of IRWST using PIV measurement, Int. J. Heat Mass Transf. 136 (2019) 128-145. doi:10.1016/j.ijheatmasstransfer.2019.01.067.

[15] Q. Wu, C. an Zhu, L. Liu, J. Liu, Z. Luo, Two-dimensional flow visualization and velocity measurement in natural convection near indoor heated surfaces using a thermal image 
velocimetry method, Appl. Therm. Eng. $146 \quad$ (2019) 556-568. doi:10.1016/j.applthermaleng.2018.10.023.

[16] W. Gao, R.H. Shaw, K.T. Paw U, Observation of organized structure in turbulent flow within and above a forest canopy, Boundary-Layer Meteorol. 47 (1989) 349-377. doi:10.1007/BF00122339.

[17] F. Castellví, C. Cammalleri, G. Ciraolo, F. Rossi, Daytime sensible heat flux estimation over heterogeneous surfaces using multitemporal land-surface temperature observations. Water Resour. Res. 52 (2016) 3457-3476.

[18] G.M. Carlomagno, G. Cardone, Infrared thermography for convective heat transfer measurements, 2010. doi:10.1007/s00348-010-0912-2.

[19] M. Aminzadeh, D. Breitenstein, D. Or, Characteristics of Turbulent Airflow Deduced from Rapid Surface Thermal Fluctuations: An Infrared Surface Anemometer, Boundary-Layer Meteorol. (2017) 1-16. doi:10.1007/s10546-017-0279-5.

[20] E. Haghighi, D. Or, Thermal signatures of turbulent airflows interacting with evaporating thin porous surfaces, Int. J. Heat Mass Transf. 87 (2015) 429-446.

[21] C.J. Legleiter, P.J. Kinzel, J.M. Nelson, Remote measurement of river discharge using thermal particle image velocimetry (PIV) and various sources of bathymetric information, J. Hydrol. 554 (2017) 490-506. doi:10.1016/j.jhydrol.2017.09.004.

[22] T. Lopez, H.E. Thomas, A.J. Prata, A. Amigo, D. Fee, D. Moriano, Volcanic plume characteristics determined using an infrared imaging camera, J. Volcanol. Geotherm. Res. 300 (2014) 148-166. doi:10.1016/j.jvolgeores.2014.12.009.

[23] A. Tiddens, K. Risthaus, M. Röger, H. Stadler, B. Hoffschmidt, Induced Infrared Thermography: Flow visualizations under the extreme conditions of an open volumetric receiver of a solar tower, Int. J. Heat Fluid Flow. 65 (2017) 105-113. doi:10.1016/j.ijheatfluidflow.2017.04.002.

[24] Z.C. Huang, K.S. Hwang, Measurements of surface thermal structure, kinematics, and turbulence of a large-scale solitary breaking wave using infrared imaging techniques, Coast. Eng. 96 (2015) 132-147. doi:10.1016/j.coastaleng.2014.12.005.

[25] A. Inagaki, M. Kanda, S. Onomura, H. Kumemura, Thermal Image Velocimetry, Boundary-Layer Meteorol. 149 (2013) 1-18. doi:10.1007/s10546-013-9832-z.

[26] Y. Fan, Y. Li, S. Yin, Non-uniform ground-level wind patterns in a heat dome over a uniformly heated non-circular city, Int. J. Heat Mass Transf. 124 (2018) 233-246. doi:10.1016/j.ijheatmasstransfer.2018.03.069.

[27] E. Lev, M. Spiegelman, R.J. Wysocki, J.A. Karson, Investigating lava flow rheology using video analysis and numerical flow models, J. Volcanol. Geotherm. Res. 247-248 (2012) 62-73. doi:10.1016/j.jvolgeores.2012.08.002.

[28] A. Garai, J. Kleissl, Air and Surface Temperature Coupling in the Convective Atmospheric Boundary Layer, J. Atmos. Sci. 68 (2011) 2945-2954. doi:10.1175/JAS-D-11-057.1.

[29] M. Katurji, P. Zawar-reza, Forward-Looking Infrared Cameras for Micrometeorological Applications within Vineyards, Sensors. 16 (2016) 2-11. doi:10.3390/s16091518.

[30] A.M. Grudzielanek, J. Cermak, Capturing Cold-Air Flow Using Thermal Imaging, Boundary-Layer Meteorol. 157 (2015) 321-332. doi:10.1007/s10546-015-0042-8.

[31] A. Koca, G. Cetin, Experimental investigation on the heat transfer coefficients of radiant heating systems: Wall, ceiling and wall-ceiling integration, Energy Build. 148 (2017) 
311-326. doi:10.1016/j.enbuild.2017.05.027.

[32] X. Zhang, G. Su, J. Yu, Z. Yao, F. He, PIV measurement and simulation of turbulent thermal free convection over a small heat source in a large enclosed cavity, Build. Environ. 90 (2015) 105-113. doi:10.1016/j.buildenv.2015.03.015.

[33] H. Karatas, T. Derbentli, Natural convection and radiation in rectangular cavities with one active vertical wall, Int. J. Therm. Sci. 123 (2018) 129-139.

[34] H. Karatas, T. Derbentli, Natural convection in rectangular cavities with one active vertical wall, Int. J. Heat Mass Transf. 105 (2017) 305-315.

[35] H. Karatas, T. Derbentli, Three-dimensional natural convection and radiation in a rectangular cavity with one active vertical wall, Exp. Therm. Fluid Sci. 88 (2017) 277-287. doi:10.1016/j.expthermflusci.2017.05.025.

[36] TL. Bergman, AS. Lavine, FP. Incropera, DP. DeWitt, Fundamentals of Heat and Mass Transfer: Seventh Edition, John Wiley \& Sons, 2011.

[37] YF. Liu, ZY. Gao, XJ. Gao, Heat transfer, China Electric Power Press, 2015.

[38] G. Hetsroni, T.A. Kowalewski, B. Hu, A. Mosyak, Tracking of coherent thermal structures on a heated wall by means of infrared thermography, 30 (2001) 286-294.

[39] Y. Cheng, Z. Lin, Experimental study of airflow characteristics of stratum ventilation in a multi-occupant room with comparison to mixing ventilation and displacement ventilation, Indoor Air. 25 (2015) 662-671. doi:10.1111/ina.12188.

[40] Q. Ouyang, W. Dai, H. Li, Y.Z. Ã, Study on dynamic characteristics of natural and mechanical wind in built environment using spectral analysis, 41 (2006) 418-426..

[41] M. Lesieur. Turbulence in fluids, Springer, 2008.

[42] X. Zhang, J. Yu, G. Su, Z. Yao, P. Hao, F. He, Statistical analysis of turbulent thermal free convection over a small heat source in a large enclosed cavity, Appl. Therm. Eng. 93 (2016) 446-455. doi:10.1016/j.applthermaleng.2015.10.011. 